\title{
Review of the assessment of two stocks of Antarctic minke whales (eastern Indian Ocean and western South Pacific)
}

\author{
Hiroto Murase ${ }^{1 *}$, Debra Palka ${ }^{2}$, André E. Punt $^{3}$, Luis A. Pastene ${ }^{4}$, Toshihide Kitakado 5 , Koji Matsuoka ${ }^{4}$, \\ Takashi Hakamada ${ }^{4}$, Hiroshi OKamura ${ }^{6}$, Takeharu Bando ${ }^{4}$, Tsutomu Tamura $^{4}$, Kenji Konishi ${ }^{4}$, Genta Yasunaga ${ }^{4}$, \\ TATSUYA ISODA ${ }^{4}$ AND HIDEHIRO KATO ${ }^{4,5}$
}

\begin{abstract}
An in-depth assessment of an eastern Indian stock (I-stock) and a western South Pacific stock (P-stock) of Antarctic minke whales distributed between $35^{\circ} \mathrm{E}$ and $145^{\circ} \mathrm{W}$ was carried out by the Scientific Committee of the International Whaling Commission (IWC/SC) from 2001 to 2014 using data mainly collected from 1985 to 2004. This paper is a synthesis and summary of the outcomes of that assessment, although research on this species has been ongoing since 2014. The assessment integrates information from a wide range of topics including systematics, survey methods, direct catches, population structure, abundance, spatial distribution, biological information, population dynamics, species interactions, pollutants and interactions with marine debris. At least two stocks (I-stock and P-stock) are found between $35^{\circ} \mathrm{E}-145^{\circ} \mathrm{W}$, with a soft boundary between $100^{\circ} \mathrm{E}$ and $165^{\circ} \mathrm{E}$. Two sets of agreed circumpolar estimates of abundance from IWC assessment cruises (termed 'CPII' - 1985/86-1990/91, and 'CPIII' - 1991/92-2003/04) were obtained; a null hypothesis of no change in overall abundance between CPII and CPIII was not rejected. The results of a Statistical Catch-at-Age Analysis (SCAA) applied to the two stocks revealed that (1) abundance increased from 1930 until the mid-1970s, and declined over the period from the mid-1970s until the late-1980s and (2) trends in abundance over the most recent 20 years were relatively flat for the I-stock but decreasing for the P-stock. Although the primary focus at the start of this assessment was to try to understand abundance trends during the 1985-2004 period, it expanded to increasing knowledge on the life history of this species. The assessment also advanced many aspects of analytical methods.
\end{abstract}

KEYWORDS: ANTARCTIC; ENVIRONMENT; EXPLOITATION; FEEDING; MARINE DEBRIS; POLLUTION; POPULATION ASSESSMENT; POPULATION PARAMETERS; REPRODUCTION; SOUTHERN OCEAN; STOCK IDENTITY

\section{INTRODUCTION}

The Antarctic minke whale (Balaenoptera bonaerensis, Burmeister, 1867; see 'Systematics' below, the IWC has only recognised the Antarctic minke whale as a separate species since 2000) has a narrow pointed rostrum, and a single head ridge (Fig. 1). It resides in the Southern Hemisphere, spending the austral summer feeding season in waters all around the Antarctic. Most animals are believed to winter between about $7^{\circ}$ and $35^{\circ} \mathrm{S}$, where breeding occurs, although some individuals are found in the Antarctic in winter. Observations of whales between $35^{\circ}-50^{\circ} \mathrm{S}$ suggest that the major proportion of whales from the breeding grounds migrate south from about October to feeding areas in the Antarctic to arrive on average by January. The highest densities during the feeding season are along the ice edge, with some animals located within the pack ice.

\section{The 1990 'Comprehensive Assessment'}

A 'Comprehensive Assessment' $(\mathrm{CA})^{7}$ of what were then called Southern Hemisphere minke whales was completed by the Scientific Committee of the International Whaling

\footnotetext{
${ }^{7}$ In the context of the IWC/SC, a Comprehensive Assessment (CA) can be considered as the first in-depth evaluation of the status of a species in an ocean area complex in the light of management objectives and procedures. Subsequent assessments are known as in-depth assessments (IA) (IWC, 1987; 2019).
}

Commission (IWC/SC) in 1990 (IWC, 1991a, b). This assessment focused on minke whales south of $60^{\circ} \mathrm{S}$ in the austral summer. These whales are now considered to be Antarctic minke whales (see 'Systematics' below). The effect of historical catches on the status of the stock was evaluated in two ways: by comparing the total catches to the then current abundance estimate, and by using the program HITTER, a stock assessment population dynamics model (de la Mare, 1989). At that time, the IWC used the six traditional baleen whale management Areas (I-VI; Fig 2) for minke whales in the Southern Hemisphere. These were not based upon analysis of minke whale data (see discussion in Donovan, 1991). During the CA, population structure discussions were based upon a variety of minke whale data types (e.g. genetics, markrecapture, morphometry, distribution). There was no agreement on a single stock structure hypothesis and so several alternatives were put forward. The final assessment used HITTER to evaluate the effects of historical catches within each of the six Areas as well as for the whole circumpolar region. However, there was no consensus within the IWC/SC on the implications of the various analyses for management ${ }^{8}$.

\footnotetext{
${ }^{8}$ At that time, whilst the so-called New Management Procedure (NMP) was still the official IWC approach for calculating catch limits and classifying stocks, what is now known as the Revised Management Procedure (RMP) was nearing completion but was not finalised and accepted by the IWC until 1994 (IWC, 1995a).
}

${ }^{1}$ National Research Institute of Far Seas Fisheries, Japan Fisheries Research and Education Agency, 2-12-4 Fukuura, Kanazawa, Yokohama, Kanagawa 236-8648, Japan.

${ }^{2}$ NOAA Fisheries, Northeast Fisheries Science Center, 166 Water Street, Woods Hole, Massachusetts, 02543, USA.

${ }^{3}$ School of Aquatic and Fishery Sciences, University of Washington, Box 355020, Seattle, WA 98195-5020, USA.

${ }^{4}$ The Institute of Cetacean Research, 4-5 Toyomi-cho, Chuo-ku, Tokyo 104-0055, Japan.

${ }^{5}$ Tokyo University of Marine Science and Technology, 4-5-7 Konan, Minato-ku, Tokyo 108-8477, Japan.

${ }^{6}$ National Research Institute of Fisheries Science, Fisheries Research Agency, 2-12-4 Fukuura, Kanazawa, Yokohama, Kanagawa 236-8648, Japan.

* Current address: Tokyo University of Marine Science and Technology, 4-5-7 Konan, Minato-ku, Tokyo 108-8477, Japan. 

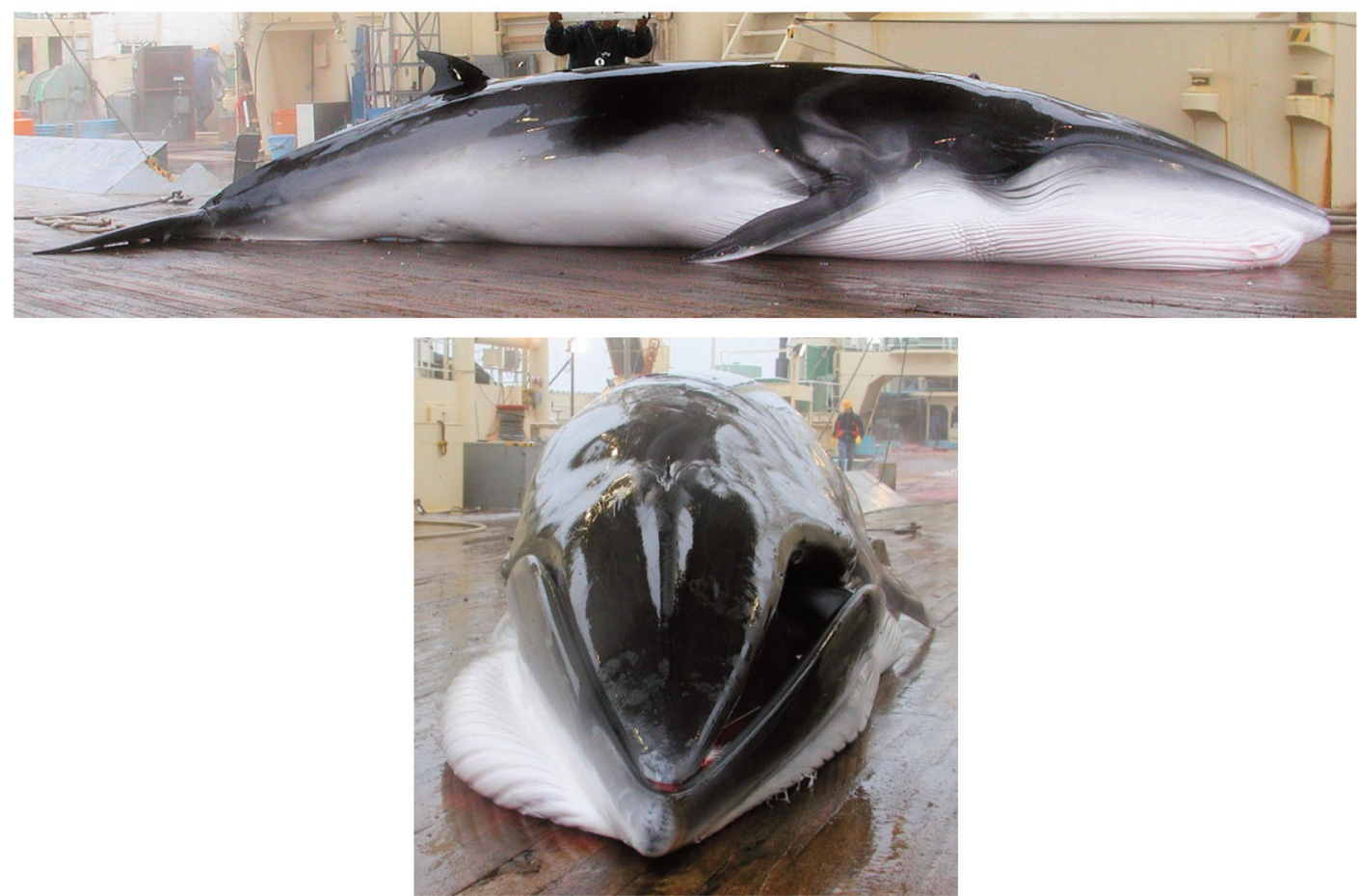

Fig. 1. Lateral view showing flipper and dorsal fin (top), and a view of the head (bottom) of B. bonaerensis.

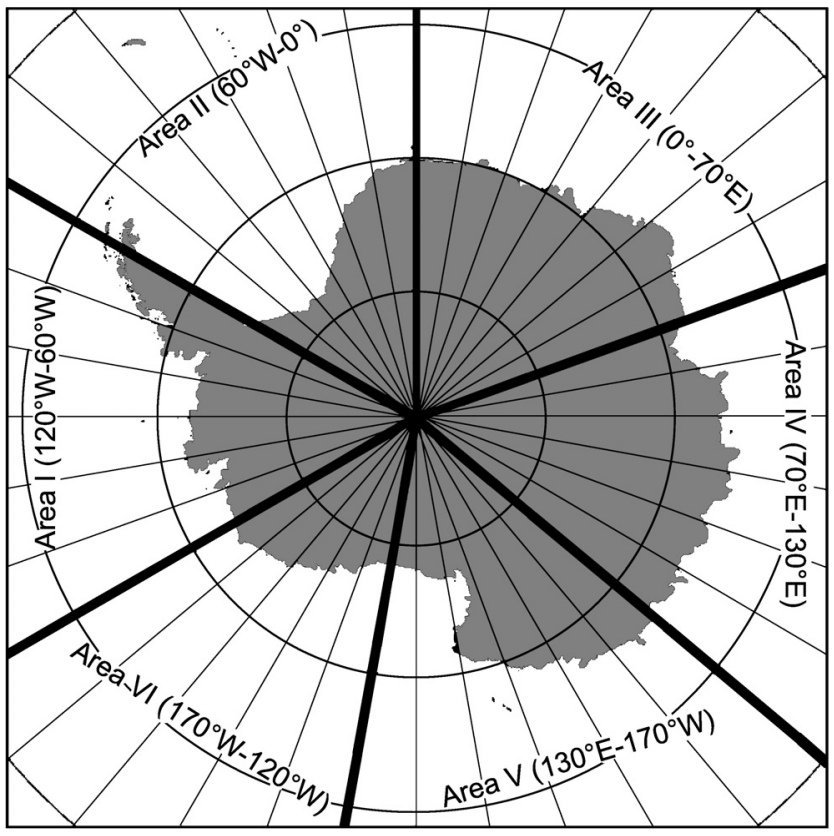

Fig. 2. Six Management Areas (Areas I-VI) for Southern Hemisphere baleen whale species (apart from the Bryde's whale) formally established by the International Whaling Commission (IWC).

The estimates of abundance applied during the CA (IWC, 1991a, table 1, p.59) were for each Area using data obtained during the IWC's International Decade of Cetacean Research (IDCR) sighting surveys collected during 1979/80-1988/89, which corresponded to whole first (CPI) and a part of the second set of circumpolar (CPII) surveys (see 'The IWC's IDCR/SOWER programmes' below). These estimates were considered negatively biased since areas north of $60^{\circ} \mathrm{S}$ and within the pack ice could not be surveyed and $g(0)$ was assumed to be equal to 1 , i.e. all whales on the trackline were seen. Demographic parameter values used in HITTER included an age at recruitment of 7 , an age at sexual maturity of 7.5, and a natural mortality rate of $0.105 \mathrm{yr}^{-1}$. The maximum sustainable yield level (MSYL) was set at the 'traditional' $60 \%$ of carrying capacity but was set at $80 \%$ as a sensitivity test for Areas II and IV. The MSY rate (in terms of the mature component of the population) was set to 0,1 , 2,3 or $4 \%$ as summarised in table 2 of IWC (1991a, p.61). Those members of the IWC/SC who considered the HITTER model appropriate, interpreted the results to indicate that the exploited female component of most stocks was at the high end of the range of 50-90\% of carrying capacity, under the assumption that the carrying capacity had been constant before 1972. Those members who considered that the only useful indication of the status of the stocks came from a comparison of the 'current' stock abundance estimate with the total cumulative catch concluded that the abundance of minke whales in Areas V and VI had been little changed by those catches. They also concluded that the abundance in Areas I and II had not been affected to an extent that would raise questions as to whether the historical rates of exploitation had been too high. However, they considered that Areas III and IV had experienced catches that raised the question of whether lower rates of exploitation would have been desirable. They also believed that because there had been a tendency for catching to concentrate on the Area III/ IV boundary, such catches could have led to greater depletion in the boundary region if the assumed stock boundary did not in fact divide two stocks which mix fully and rapidly within the greater areas of the putative stock divisions. Ecosystem considerations were also discussed, although no conclusions were drawn.

\section{The 2001-14 In-depth Assessment}

The IWC/SC agreed in 2000 to undertake an in-depth assessment (IA) that would evaluate the status of the Antarctic minke whale that would involve an examination of current stock size, recent population trends, carrying 
capacity and productivity (IWC, 2001a). Initially, this had been planned as simply a review of abundance estimates (IWC, 2000), but it was later decided to integrate biological information and population dynamics and undertake a full assessment (IWC, 2001a). In particular, the IWC/SC considered it urgent to address abundance trend-related issues to provide up-to-date estimates of minke whale abundance. At that time, it was noted that while the estimates of the minke population sizes accepted in the $1990 \mathrm{CA}$, which totalled some 760,000 and were obtained using CPI and CPII data from $1979 / 80$ to $1988 / 89$, were the best available at the time, they were no longer appropriate estimates of then current (2000) minke whale abundance. This was because some crude extrapolations of the incomplete third circumpolar set of surveys (CPIII) led to a point estimate that was appreciably lower than the total of the previously agreed point estimates by Area from the 1990 CA (Branch and Butterworth, 2001a).

It took until 2014 to examine all the issues, develop new methods, incorporate more recent data and complete an updated assessment of the status of the Antarctic minke whales in the east Indian to western South Pacific region. This paper summarises the outcomes of the analyses conducted from 2001 to 2014, although research on this species remains ongoing. The review covers systematics, survey methods, direct catches, population structure, abundance, spatial distribution, biological information, population dynamics, species interactions, pollutants and interactions with marine debris. The focus was on an eastern Indian stock and a western South Pacific stock, distributed from Area III-E to Area VI-W $\left(35^{\circ} \mathrm{E}\right.$ to $145^{\circ} \mathrm{W}$; Table 1) where most of the available data were from. An IA of Antarctic minke whales in the rest of the Antarctic has not yet been started although some abundance estimates are available (IWC, 2013a).

Table 1

Longitudinal ranges of eastern and western strata of Areas III, IV, V and VI.

\begin{tabular}{ccc}
\hline Area and stratum & Abbreviation & Longitudinal range \\
\hline III East & III-E & $35^{\circ} \mathrm{E}-70^{\circ} \mathrm{E}$ \\
IV West & IV-W & $70^{\circ} \mathrm{E}-100^{\circ} \mathrm{E}$ \\
IV East & IV-E & $100^{\circ} \mathrm{E}-130^{\circ} \mathrm{E}$ \\
V West & V-W & $130^{\circ} \mathrm{E}-165^{\circ} \mathrm{E}$ \\
V East & V-E & $165^{\circ} \mathrm{E}-170^{\circ} \mathrm{W}$ \\
VI West & VI-W & $170^{\circ} \mathrm{W}-145^{\circ} \mathrm{W}$ \\
\hline
\end{tabular}

\section{SYSTEMATICS}

Until relatively recently, only one species of minke whale was thought to exist: Balaenoptera acutorostrata Lacèpéde, 1804. However, Rice (1998) reviewed morphological (e.g. Williamson, 1959; van Utrecht and van der Spoel, 1962; Kasuya and Ichihara, 1965; Omura, 1975; Best, 1985) and genetic (e.g. Wada et al., 1991; Arnason et al., 1993; Pastene et al., 1994) data collected from extant minke whale populations and re-specified two species, the Antarctic minke whale B. bonaerensis Burmeister, 1867, which is restricted to the Southern Hemisphere, and the common minke whale B. acutorostrata Lacèpéde, 1804, which is distributed globally. Furthermore, he recognised three sub-species of the common minke whale, one in the North Pacific, one in the North Atlantic and one in the Southern Hemisphere. In the Southern Hemisphere, the common minke whale is referred to as the 'dwarf' or 'diminutive' minke whale (Best, 1985; Arnold et al., 1987; Kato and Fujise, 2000; Kato et al., 2015) and is rarely found south of $60^{\circ} \mathrm{S}$. The two species in the Southern Hemisphere have not been confused during the sighting surveys conducted using closing mode because of the distinctive morphological features of the two species. According to the descriptions for identification on the two species by Kato et al. (2015), the two species can be clearly distinguished by the presence of white patch overspread on the shoulder-flipper portion in dwarf minke whales in contrast to Antarctic minke whales which lack them. The Antarctic minke whale can be distinguished in the field by its larger size and by a dorsal fin that is set farther back on the body. The dwarf minke whale has a very distinctive white patch on its flipper, unlike the light gray flipper of the Antarctic minke whale.

In 2000, the IWC/SC recognised the two species but deferred a decision on other nominal taxa until the completion of a worldwide review of genetic and nongenetic information for minke whales (IWC, 2001b). Subsequent worldwide genetic analyses of minke whales provided further evidences for the separation of the two species, B. bonaerensis and B. acutorostrata, and at least three sub-species of the common minke whale as recognised by Rice (1998) using mitochondrial DNA sequences (Fig. 3; Pastene et al., 2010) and microsatellites (Glover et al., 2013). It has been hypothesised that the two species diverged in the Southern Hemisphere less than 5 million years ago, and that the current sub-species of $B$. acutorostrata diverged after the Pliocene some 1.5 million years ago (Pastene et al., 2007). However, recent genetic studies have provided evidence of migration of individuals of the Antarctic species to the Arctic Northeast Atlantic (Glover et al., 2010; 2013). Whether these migrations represent contemporary events or have occurred at a low frequency over many years, remains an open question.

In addition to the genetic information there are differences in external appearance, morphometrics, distribution and other biological features. For example, the estimated body length at physical maturity for North Pacific common minke whale was $7.5 \mathrm{~m}$ for males and $8.0 \mathrm{~m}$ for females (Kato, 1992), $8.2 \mathrm{~m}$ for males and $8.8 \mathrm{~m}$ for females of the North Atlantic common minke whale (Jonsgård, 1951), 6.6m for males and $7.0 \mathrm{~m}$ for females of the dwarf minke whale (Kato and Fujise, 2000; Kato et al., 2015), and $8.5 \mathrm{~m}$ for males and $9.2 \mathrm{~m}$ for females of the Antarctic minke whale (Bando, pers. comm.). Nakamura et al. (2014) reported on variation in the colour patterns of the white patch on the flippers between North Pacific and North Atlantic common minke whales.

Consequentially, after reviewing all available information, the Committee of Taxonomy of the Society for Marine Mammalogy listed the following species and sub-species of minke whale (Committee on Taxonomy, 2016):

(1) Balaenoptera acutorostrata Lacèpéde, 1804. Common minke whale

(a) B. a. acutorostrata Lacèpéde, 1804. North Atlantic minke whale 

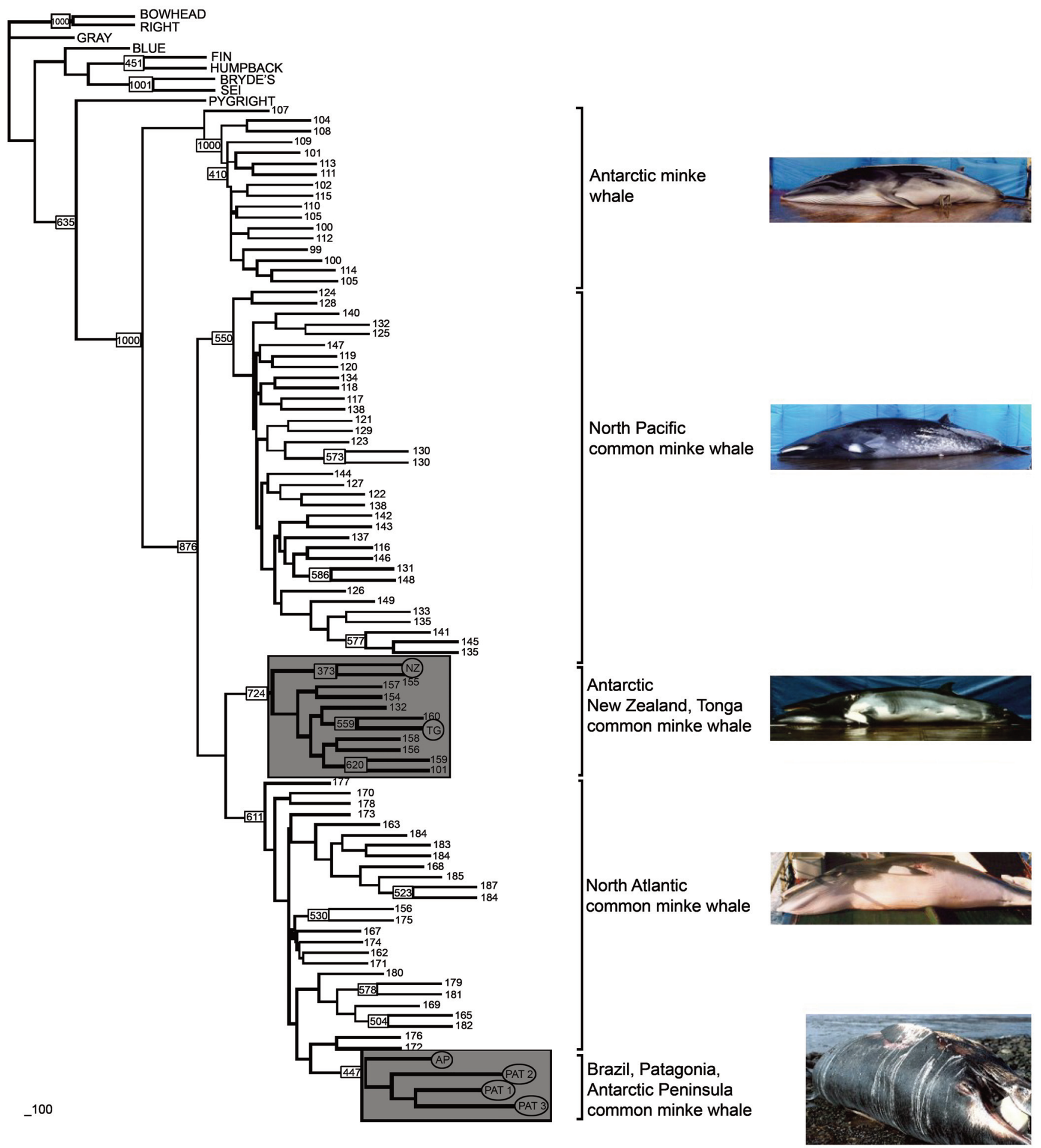

Fig. 3. Phylogeneny of mtDNA haplotypes of minke whale worldwide (modified version of Pastene et al., 2010).

(b) B. a. scammoni Deméré, 1986. North Pacific minke whale

(c) B. $a$. un-named subsp. Dwarf minke whale

(2) Balaenoptera bonaerensis Burmeister, 1867. Antarctic minke whale

While additional genetic and morphological/morphometric studies are required to elucidate further the taxonomic status within $B$. acutorostrata, including that of the dwarf minke whale, there is agreement on the taxonomic status of $B$. bonaerensis, the species that is the focus of this IA.

\section{MAIN DATA SOURCES}

The IWC's IDCR/SOWER programmes

The IWC Southern Hemisphere minke whale assessment cruises (IDCR and the subsequent survey program, SOWER (Southern Ocean Whale and Ecosystem Research) from 1996/97) has been conducted since 1978/79 in all six IWC Antarctic management Areas (covering all, or more recently, part, of one Area each season). In total, up to the 2009/10 austral summer season, this involved 32 shipborne surveys (4,340 ship-days, 70 vessels and 240 international researchers from 15 nations). These constitute three circumpolar sets: 
1978/79-1983/84 (CPI), 1985/86-1990/91 (CPII) and 1991/ 92-2003/04 (CPIII), and further there were experimental cruises from $2004 / 05$ to $2009 / 10$. The $1984 / 85$ (first half) and 2004/05-2009/10 surveys were devoted mostly to experiments and are excluded when estimating abundance for the IA. These surveys were conducted in the open sea because the survey vessels were not ice strengthened. Survey methods up to 2000/01 were reviewed by Matsuoka et al. (2003). From 1978/79, the start of CPI, surveys were a combination of Discovery marking (with the objective of obtaining mark-recapture estimates - see Buckland and Duff, 1989) and sighting surveys. From 1985/86, the start of CPII, the programme became essentially a dedicated line-transect systematic sighting survey, where the passing mode used in CPI was augmented with an additional independent observer (IO mode) to provide data for the estimation of $g(0)$. From 1991/92, the start of CPIII, the objective was modified to cover the whole region south of $60^{\circ} \mathrm{S}$ in the Antarctic, which resulted in a change in emphasis regarding the extent of the latitudinal coverage, especially in Areas I, II, III and V.

The sightings data from CPI to CPIII have been encoded and validated and stored in a database package DESS 3.5 (IWC Database-Estimation Software System v 3.5; Strindberg and Burt, 2004). For the 2001-14 IA, a standard data set was extracted from DESS for abundance estimation of Antarctic minke whales for CPII and CPIII (Burt, 2004). Data from these IWC surveys can be requested from the IWC Secretariat ${ }^{9}$.

Although the primary aim of the surveys was to estimate Antarctic minke whale abundance, all cetacean sightings were recorded, which made it possible to estimate abundance for species other than Antarctic minke whales (e.g. see Branch and Butterworth, 2001b). The survey programme has also enabled collection of biopsies, photo-identification, oceanographic and acoustic samples. In addition, a series of experiments was carried out from 2004/05 to 2009/10 to address problems encountered with the analysis of abundance data from previous cruises. These included implementing the Buckland-Turnock survey methodology (Buckland and Turnock, 1992), school size estimation experiments and dive time experiments.

\section{Japan's JARPA/JARPAII special permit programmes}

The Government of Japan conducted the Japanese Whale Research Program under Special Permit in the Antarctic (JARPA) from 1987/88 to 2004/05 under Article VIII of the International Convention for Regulation of Whaling (ICRW). There were two original objectives for this programme: (1) estimation of biological parameters to improve the stock management of the Antarctic minke whale (this included estimation of the age-dependence of natural mortality and reproductive parameters such as age at sexual maturity and their changes over time); and (2) elucidation of the role of whales in the Antarctic marine ecosystem (Government of Japan, 1987; 1989). Modelling and statistical analysis were used to address objective (1), while the abundance of each whale species and the diet of the Antarctic minke whale were examined to address objective (2). A third objective, elucidation of the effect of environmental change

${ }^{9}$ https://iwc.int/sower. on cetaceans, was added in 1995/96 in response to the IWC's resolution regarding to environment and pollution (IWC, 1994; Government of Japan, 1995). A fourth objective, elucidation of the stock structure of Southern Hemisphere minke whales to improve stock management was added in 1996/97 (Government of Japan, 1996). Initially, the surveys were conducted each year, alternating between Areas IV and V. The survey area was expanded to include Area III-E and Area VI-W in 1995/96 to improve research on the stock structure of Antarctic minke whales. Subsequently, Areas III East + IV and Areas V + VI West were surveyed alternately each season. Two or three sighting and sampling vessels (SSVs) conducted sighting and sampling surveys. A dedicated sighting vessel (SV) was introduced from the 1991/92 season. The Antarctic minke whales sampled were examined on a research base vessel. The general survey methodology has been summarised by Nishiwaki et al. (2006).

The Government of Japan conducted the Japanese Whale Research Program under Special Permit in the AntarcticPhase II (JARPAII) (Government of Japan, 2005) from 2005/06 to 2013/14. JARPAII had four objectives: (1) monitoring of the Antarctic ecosystem; (2) modelling competition among whale species and future management objectives; (3) elucidation of temporal and spatial changes in stock structure; and (4) improving the management procedure for Antarctic minke whale stocks. Areas III-E + IV and Areas V + VI-W were surveyed alternately each season. Two or three SSVs conducted sighting and sampling surveys, while one or two SVs conducted sighting surveys. The Antarctic minke whales sampled were again examined on a research base vessel. The general survey methodology has been summarised by Nishiwaki et al. (2014).

There have been three IWC/SC reviews of the JARPA and JARPAII programmes (IWC, 1998; 2008b; 2015c) that also informed the IA.

\section{Surveys within sea ice}

As noted above, a limitation of the IDCR/SOWER/JARPA/ JARPAII surveys was that they could not enter the ice. To address this limitation, other surveys were conducted by icebreakers within the sea ice to investigate the density of whales in these regions. These surveys were considered platforms of opportunity surveys rather than dedicated systematic sighting surveys. Cetacean sightings data were collected from the following icebreakers:

(1) The US icebreaker, Nathaniel B. Palmer, which surveyed between $150^{\circ} \mathrm{W}$ and $70^{\circ} \mathrm{W}$ in February-March 1994 (Ainley et al., 2007);

(2) The Australian icebreaker, Aurora Australis, which surveyed in the sea ice field between $77^{\circ} 50^{\prime} \mathrm{E}$ and $150^{\circ} 50^{\prime} \mathrm{E}$ in November-December 1999 as a part of the Antarctic Pack Ice Seal (APIS) circum-Antarctic surveys and the Southern Ocean Cetacean Ecosystem Program (SOCEP) (collectively termed as APIS/SOCEP) (Thiele et al., 2002);

(3) The US icebreaker, Nathaniel B. Palmer, which surveyed in the Ross Sea in 2004 as part of the US Antarctic Slope (AnSlope) experiment (Thiele et al., 2005); and 
(4) The Japanese icebreaker, Shirase, which surveyed in the sea ice field between $40^{\circ} \mathrm{E}$ and $150^{\circ} \mathrm{E}$ in the $2004 / 05$ season in collaboration with the SOWER surveys (Shimada and Kato, 2005; Ensor et al., 2005).

In addition, several cetacean sighting surveys using aircraft were conducted.

(1) The Japanese icebreaker, Shirase, supported helicopter flights over the sea ice field between $40^{\circ} \mathrm{E}$ and $150^{\circ} \mathrm{E}$ during the 2004/05 season in collaboration with the SOWER surveys (Shimada and Kato, 2005; Ensor et al., 2005).

(2) An Australian fixed-wing aircraft flew between $93^{\circ} \mathrm{E}$ and $113^{\circ} \mathrm{E}$ (part of Area IV) in 2007/08 (Kelly et al., 2008), in 2008/09 (Kelly et al., 2009) and in 2009/10 (Kelly et al., 2010). All were in collaboration with SOWER surveys (Ensor et al., 2008; 2009; Sekiguchi et al., 2010).

(3) A German icebreaker-supported helicopter flew in the Weddell Sea (part of Area II) between 2002 and 2013 (Herr et al., 2014; Scheidat, et al., 2011).

Catches by commercial and special permit expeditions Catch data for the IA were extracted from the IWC individual catch database up to the end of 2015 (IWC, 2005; Allison, 2016). A total of 80,730 Antarctic minke whales were taken by commercial $(n=70,067)$ and special permit $(n=10,663)$ expeditions in the Indo-Pacific sector of the Antarctic $\left(35^{\circ} \mathrm{E}-\right.$ $145^{\circ} \mathrm{W} ; 1956 / 57$ to $2014 / 15$; Fig. 4) and their geographic positions are shown in Fig 5; catches in the Indo-Pacific sector represent $66.2 \%$ of the total catch of Antarctic minke whales $(n=121,989)$. Whales 'lost' (struck by harpoons but not captured) are excluded in the numbers. The first catch in this sector was recorded in 1956. The UK took three individuals from $1956 / 57$ to $1959 / 60$, but most of the catches were taken by the former USSR and Japan during the remainder of the period. Commercial whaling on this species has been suspended since 1986/87. Japan issued special permits for this species since 1987/88 (see 'Japan's JARPA/JARPAII special permit programmes' above). The maximum seasonal catch (5,941 individuals) occurred in 1976/77. Individual catch data include date, position, sex and associated biological data (when collected). Considerably more data were available from whales caught under special permit.

\section{STOCK STRUCTURE}

The Antarctic minke whale, in common with the other Southern Hemisphere baleen whale species apart from the Bryde's whale (B. edeni), had been managed by the IWC based on six geographical management 'Areas' (Fig. 2). These Areas, first used during the 1974/75 austral summer season, were based mainly upon information from Mackintosh $(1942 ; 1966)$ on the distribution of catches of blue, fin and humpback whales (see review by Donovan, 1991). However, the biological evidence for the boundaries was weak, especially for the Antarctic minke whale, which was not considered when the original management Areas were established (Donovan, 1991; Hoelzel and Dover, 1989). To address this gap, several approaches have been used to identify genetic or biological stocks of Antarctic minke whales and to determine to what extent they coincide with the IWC management areas.

Studies on stock structure of the Antarctic minke whale began towards the end of the 1970s and results of genetic and non-genetic analyses were reviewed by the IWC/SC during the $1990 \mathrm{CA}$ (IWC, 1991b). All the analyses presented at the $1990 \mathrm{CA}$ were based on samples and data from commercial pelagic whaling in the Antarctic. Genetic

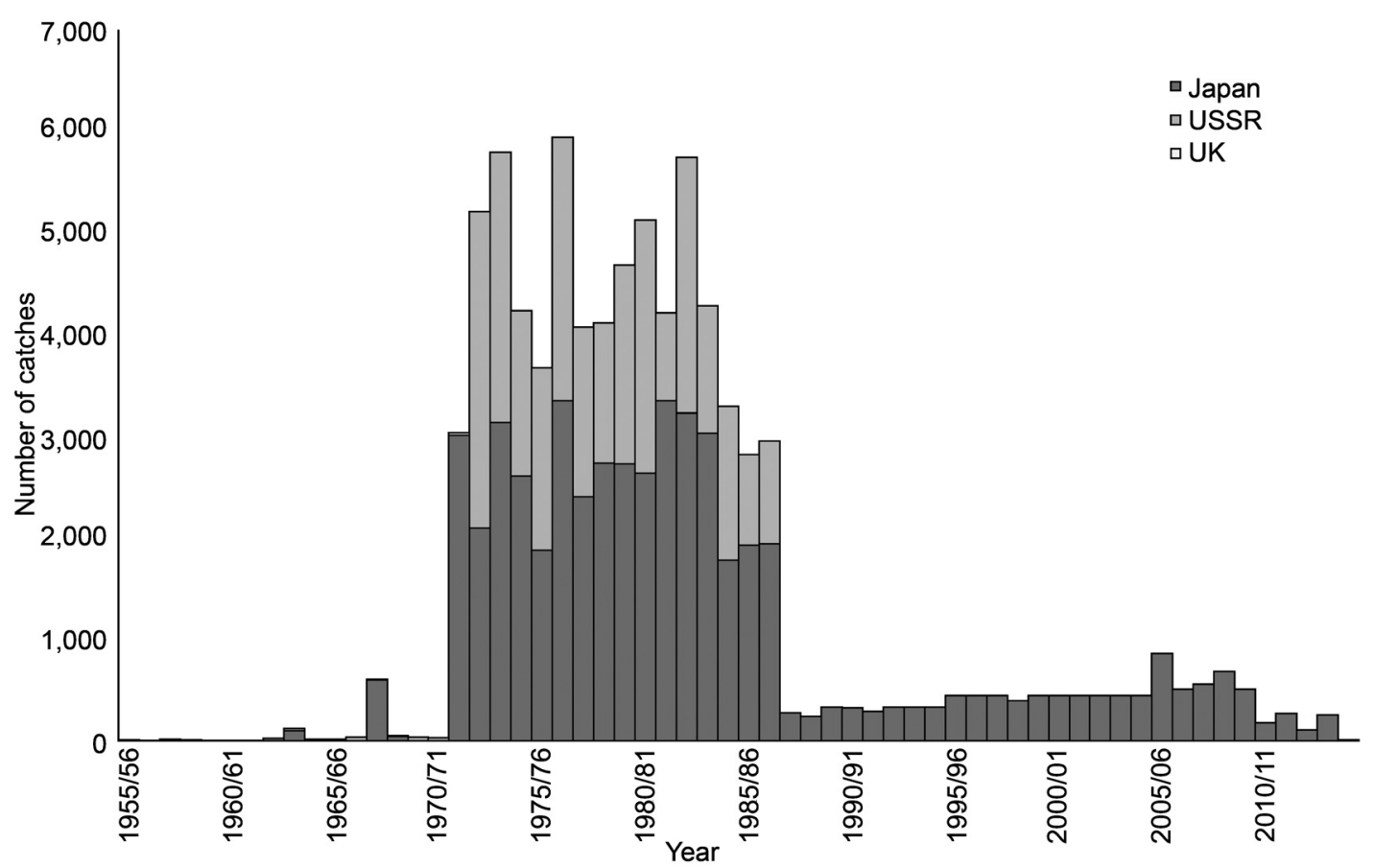

Fig 4. Number of Antarctic minke whales taken by commercial and scientific expeditions in the Indo-Pacific sector of the Antarctic $\left(35^{\circ} \mathrm{E}-145^{\circ} \mathrm{W}\right)$ from 1956 to 2015 . Whales 'lost' (struck by harpoons but not captured) are excluded in the number. The UK caught three individuals from $1956 / 57$ to $1959 / 60$, but they are virtually invisible in this figure. Catch data have been taken from Allison (2016). 


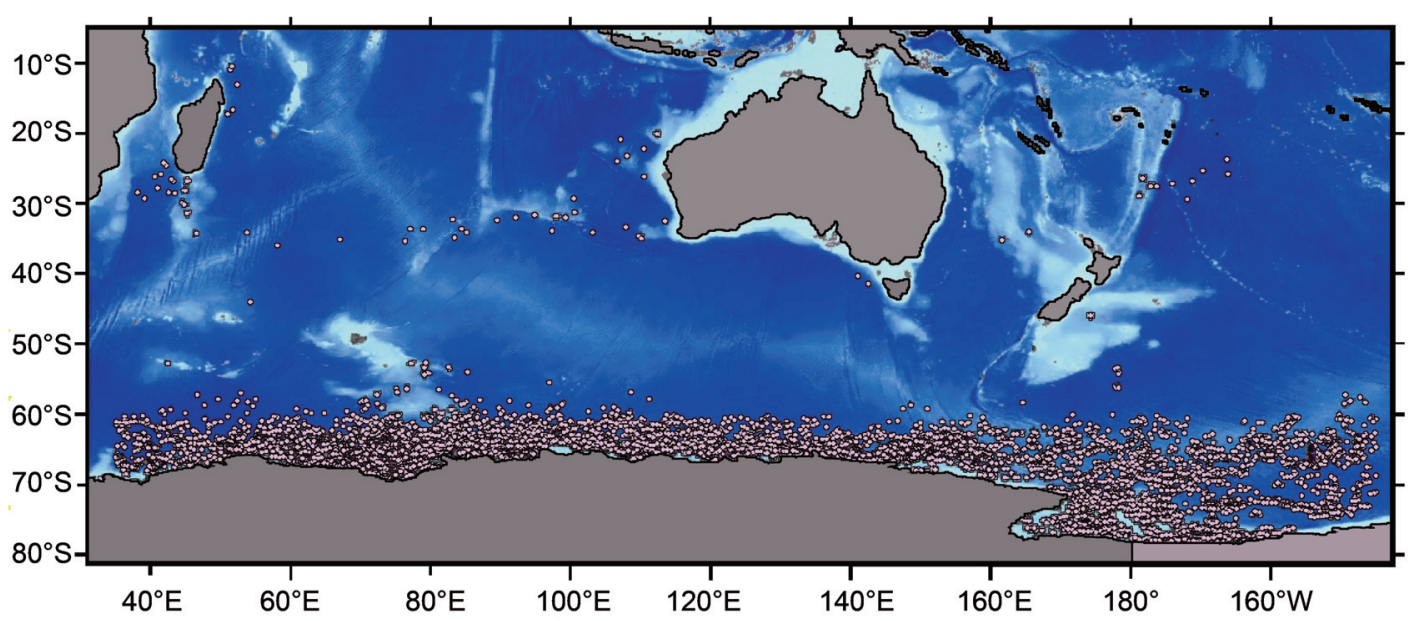

Fig. 5. Catch positions of Antarctic minke whales (pink circles) by commercial and scientific expeditions in the Indo-Pacific sector of the Antarctic $\left(35^{\circ} \mathrm{E}-145^{\circ} \mathrm{W}\right)$ from 1956 to 2014 . Catch data have been taken from Allison (2016). Bathymetry (Amante and Eakins, 2009) is shown for illustrative purposes.

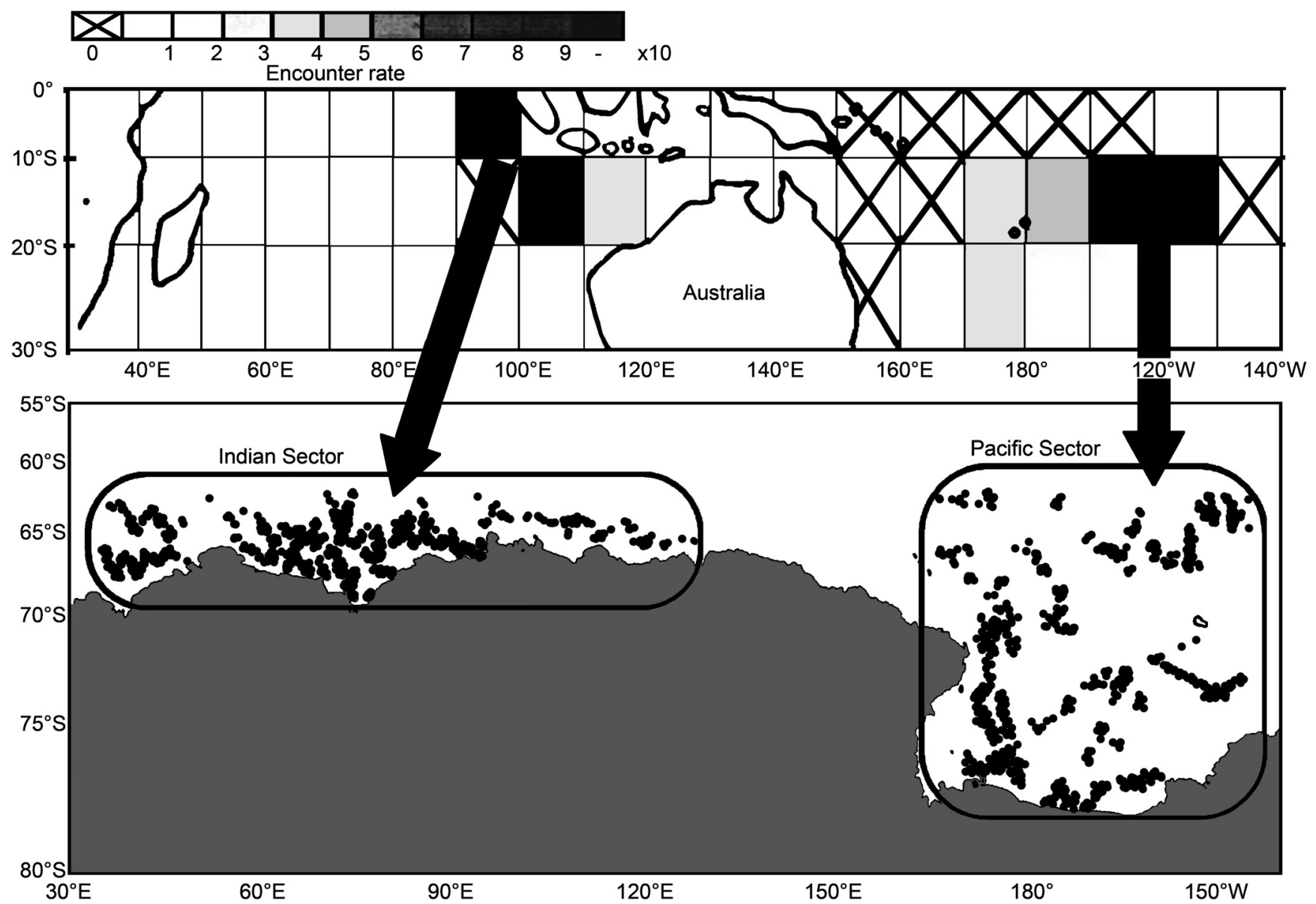

Fig. 6. Possible correspondence between areas of high sighting densities in the eastern Indian Ocean and western South Pacific (Kasamatsu et al., 1995) and feeding areas in the Antarctic (from Pastene and Goto, 2016) (see text for details).

studies were based mainly on allozymes, although studies based on mitochondrial and nuclear DNA were also conducted, and most of the analyses involved small sample sizes from Areas IV and V only. Non-genetic studies reviewed during the $1990 \mathrm{CA}$ involved morphology, catch and sighting distribution patterns, analysis of Discovery marks and ecological markers. Results from the various approaches failed to identify any isolated stock in the Antarctic unambiguously (IWC, 1991b). However, high density areas identified from analyses of Japanese Scouting Vessel (JSV) sighting data obtained during 1976-1987 in low latitudinal waters (e.g. for discussion of these data see Miyashita et al., 1993) were used to identify putative breeding grounds (IWC, 1991b, fig 1; and see Kasamatsu et al., 1995). The putative breeding grounds of minke whales found in the Areas IV and V feeding grounds were in the eastern Indian Ocean and western South Pacific, respectively (Fig. 6). 


\section{Stock structure studies leading to the 2014 IA}

The primary stock structure data sources discussed during the 2001-14 IA were from the JARPA and JARPAII programmes, both of which had stock identity as one of their objectives. Studies based upon these samples have proved to be more useful than those from the commercial period, given the wider geographical coverage and the more random sampling design. In contrast, the commercial whaling samples were taken mainly from areas of high density near the ice-edge (Pastene, 2006). Initially, the JARPA genetic studies on stock structure were based on mtDNA Restriction Fragment Length Polymorphism (RFLP), and considerable genetic heterogeneity was found in Areas IV and V (Pastene et al., 1993; 1996).

There are no genetic samples from Antarctic minke whales for the low latitudes (presumed breeding grounds) of the eastern Indian Ocean and western South Pacific to support a similar investigation of stock structure to that undertaken for humpback whales (e.g. see Schmitt et al., 2012) that suggested that the Australian continent was a natural barrier to gene flow during the winter reproductive period ${ }^{10}$. However, consideration of a suite of information from mtDNA and microsatellite DNA (Pastene et al., 2006), morphometrics for 10 external measurements (Fujise, 1995; Hakamada, 2006) and mean length at physical maturity (Bando et al., 2006a) led to the conclusion that Antarctic minke whales in the feeding grounds between Areas III-E and VI-W do not comprise a single stock (IWC, 2008b). Rather, the results are consistent with the occurrence of at least two genetic stocks in these feeding grounds, which are probably related to the two proposed breeding areas in the eastern Indian Ocean and western South Pacific (Fig. 6). The following names have been proposed for these stocks: Eastern Indian Ocean Stock (I-Stock) and Western South Pacific Ocean Stock (P-Stock) (Pastene, 2006). The analyses of the JARPA data also suggested an area of transition in the region around $150-165^{\circ} \mathrm{E}$, across which there is an as yet undetermined level and range of mixing (IWC, 2008b).

The analyses of stock structure given additional data from JARPAII were refined in two ways: the first involved additional laboratory work for additional genetic markers, and the second involved modified analytical measures. All the Antarctic minke whales taken by JARPAII between 2005/06 and 2010/11 were sequenced for a 340bp-segment of the control region of the mtDNA (instead of the mtDNA RFLP used in JARPA) and genotyped using twelve microsatellite loci (instead of the six used in JARPA). Results of the heterogeneity test for both markers showed statistically significant genetic differences between whales in the two sectors, western $\left(35-130^{\circ} \mathrm{E}\right)$ and eastern $\left(165^{\circ} \mathrm{E}-\right.$ $\left.145^{\circ} \mathrm{W}\right)$, confirming that different stocks inhabit the Indian and Pacific sectors of the Antarctic (the I- and P-stocks). Microsatellite DNA analyses showed more dispersal amongst males than females and some degree of annual variation (Pastene and Goto, 2016).

Schweder et al. (2011) developed an integrated approach for estimating longitudinal segregation of two stocks using various sources of data: morphometric, microsatellite and

${ }^{10}$ Genetic differences between western and eastern stocks of humpback whales have been detected in the Antarctic feeding grounds south of Australia (Kanda et al., 2014).
mtDNA data. A joint likelihood function was defined to estimate mixing proportions and apply statistical tests without assuming any baseline populations. This approach revealed that the soft boundary (or transition area) suggested previously could vary by year and sex. The approach was originally applied to the JARPA data (Schweder et al., 2011) and subsequently to JARPA and JARPAII data (Kitakado et al., 2014b). The results of this approach confirmed the occurrence of at least two stocks (I and P) in the Indo Pacific sector of the Antarctic. Furthermore, the results indicated that the spatial distribution of the two stocks had a soft boundary in Area IV-E $\left(100-130^{\circ} \mathrm{E}\right)$ and V-W $\left(130-165^{\circ} \mathrm{E}\right)$, which changes by year. Results also suggested possible sex differences in the distribution pattern of the two stocks. Consequently, the structure of the Antarctic minke whale in Areas III-E to VI-W appears to be more complex than originally thought. In summary, the IWC/SC agreed (IWC, 2008a) that there are (at least) two stocks with a wide mixing area that may change by year and sex (Fig. 7). The extent of the I-stock to the west of $35^{\circ} \mathrm{E}$ and that of P-stock to the east of $145^{\circ} \mathrm{W}$ cannot be investigated due to a lack of appropriate samples.

\section{ABUNDANCE AND DISTRIBUTION}

Estimating the abundance of minke whales in Antarctic waters only became a major topic when Antarctic minke whales became a major target for pelagic whaling in the early 1970s. Prior to that there had only been a crude (as recognised by the authors) estimate from non-systematic sightings surveys using largely arbitrary correction factors of around 23,200 for Area IV, with a suggestion from the authors that the total in the Antarctic summer may be about 70,000 but that it was probably considerably larger (Ohsumi et al., 1970). Subsequent sightings estimates were indeed larger (e.g. 299,000, Ohsumi and Masaki, 1974) but suffered from methodological issues. For a variety of reasons in the mid-1970s, it became apparent to the IWC/SC that assessment methods based on the use of CPUE (catch per unit effort data) were not appropriate. After much discussion, it was agreed that independent estimates of abundance were required. This led to the IWC/IDCR Southern Hemisphere minke whale assessment cruises (later renamed SOWER) that were initiated in the $1978 / 79$ season (IWC, 1980). In addition, starting in 1987/88, the Government of Japan began the JARPA special permit programme (later JARPAII) that incorporated sighting surveys.

\section{Abundance estimates from dedicated surveys IDCR/SOWER}

At the start of the 2001-14 IA, abundance estimates of Antarctic minke whales from the $1978 / 79$ to $1997 / 98$ IDCR/SOWER cruises were based on the 'IWC standard methodology' (Branch and Butterworth, 2001a), which had been developed by the IWC/SC over many years (IWC, 2002). The authors identified several methodological issues that still needed to be considered. These included how to properly address matters related to school size estimation (Brandão et al., 2001), data pooling by vessel and/or stratum to estimate effective search half-width (esw) and mean school size (Burt and Hughes, 2002; Hakamada and 

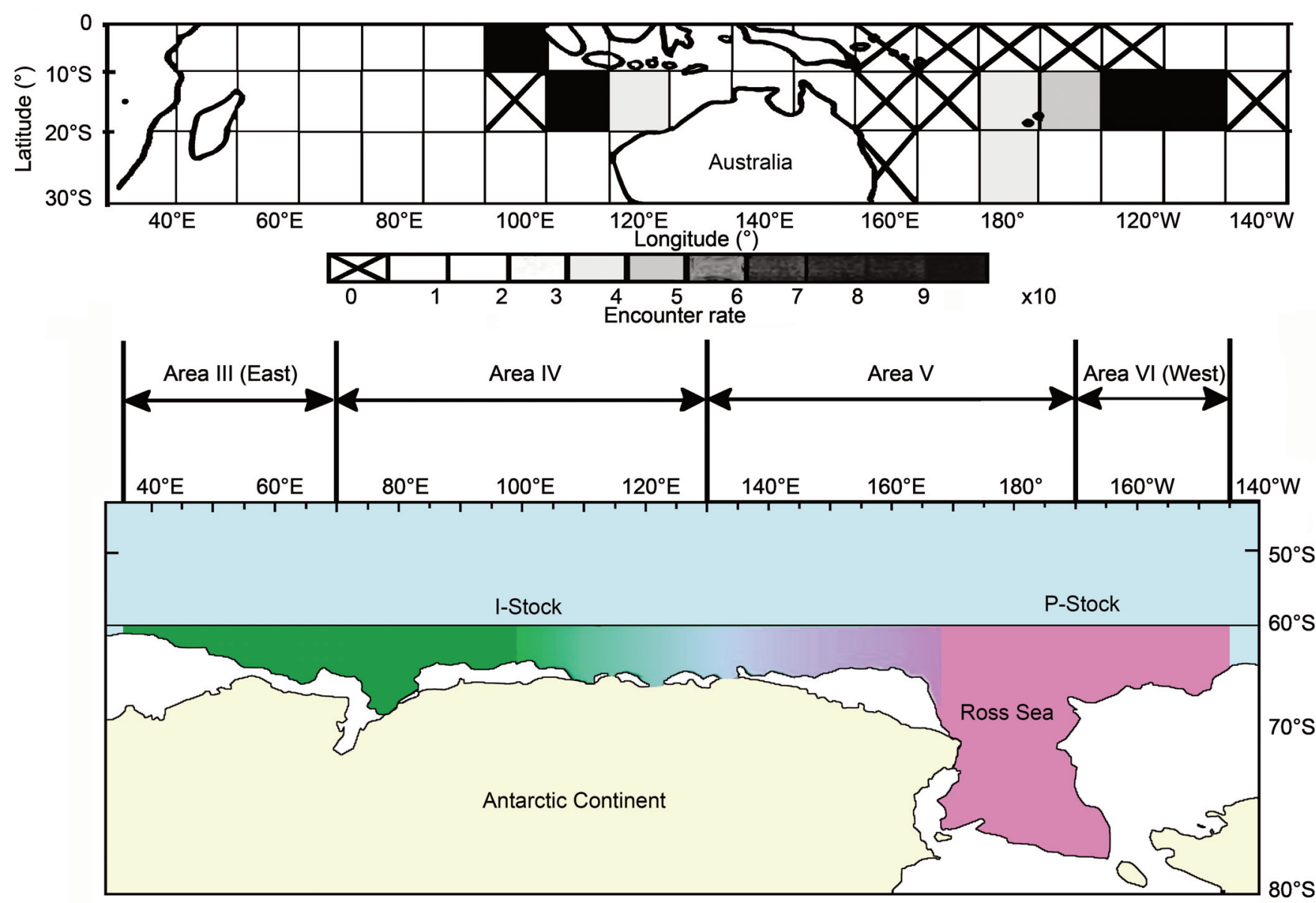

Fig. 7. Current hypothesis stock structure of the Antarctic minke whale. Two stocks (at least) occur in the research area covered during JARPA/JARPAII, which mix in a transition area, whose position and extent varies by year and sex.

Matsuoka, 2002; Matsuoka and Hakamada, 2002), use of 'like-minke' sightings (Mori et al., 2003), the closing-IO mode correction factor (Brandão and Butterworth, 2002), and areas covered by more than one survey in CPIII (Branch and Ensor, 2004; Branch 2005).

A new analysis was then undertaken using the three completed circumpolar sets of surveys from 1978/79 to 2003/2004 (Branch, 2006). Although these estimates remained negatively biased because they assumed that all schools on the trackline were detected $(g(0)=1)$, the analysis revealed a decline in estimated Antarctic minke whale numbers from CPII (1985/86-1990/91) to CPIII (1991/922003/04). Several plausible hypotheses were developed that could explain the apparent decline in estimated abundance. Consequently, given the uncertainties identified by the plausible hypotheses, the implications of the apparent declining trend to the management of Antarctic minke whales and to their ecosystem were unclear (IWC, 2003b; Murase and Bravington, 2012). Those plausible hypotheses were:

(1) Factors related to the population surveyed (e.g. changes in survey spatial-temporal coverage over years; changes in the location of the ice edge; or changes in the distribution of minke whales within the survey area and outside (within the ice and north of $60^{\circ} \mathrm{S}$ ));

(2) Factors related to the survey process (e.g. changes over time in the proportion of schools classified as 'likeminke', $g(0)$, the bias of closing relative to independent observer mode, and analysis options); and
(3) Factors related to a real decline in abundance (e.g. an increase in natural mortality or a decrease in recruitment rate due, say, to an increase in killer whales, pollution or disease; mortality due to commercial and scientific whaling; incidental mortality from bycatch and ship strikes; overshooting carrying capacity; a decrease in carrying capacity due to lower krill populations or competition from other predators; or changes in climatic conditions).

Additional analyses were conducted to explore some of these hypotheses. For example, the effect of observer efficiency was investigated (Butterworth et al., 2001; Mori et al., 2003), leading to the conclusion that this effect contributes less to differences in $g(0)$ than does school size (IWC, 2003a). The effects of sighting conditions (school size, sighting cue, latitude and sea state) on parameters related to abundance estimation for Antarctic minke whales (effective search half-width, sighting forward distance and mean school size) were investigated (Murase et al., 2004), and were considered further in abundance estimation methods taking account of $g(0)$. Mori et al. (2002) found that $g(0)$ depended on school size. New methods to incorporate covariate information into estimation of school size and esw were also presented (Borchers and Burt, 2002; Rademeyer and Butterworth, 2002). Investigations into some of the hypotheses that involve factors related to a real decline in abundance are discussed below in the Real decline plausible hypothesis investigations section. 
To address these issues, three new abundance estimation methods that accounted for $g(0)$ were initially presented by Bravington (2002), Cooke (2002) and Okamura et al. (2002) at the $2002 \mathrm{IWC} / \mathrm{SC}$ meeting. Later, these models were referred as the SPLINTR (spatial line transect), IM (integrated model) and OK (Okamura-Kitakado) methods, respectively. The OK method involved a design-based approach using a hazard probability model whereas the SPLINTR method involved a two-stage spatial modelling approach using a point independence detection function model. The IM method, which was not pursued to completion, used a hazard probability model with a spatial model based on Fourier series expansions for density. The performances and robustness of various versions of these three methods in addition to the IWC standard method were investigated using simulated data sets (Palka and Smith, 2003). OK outperformed SPLINTR for simple simulation scenarios, SPLINTR outperformed OK for simulation scenarios with complex spatial effects, whereas both OK and SPLINTR outperformed the standard method. Additional variance $(\mathrm{AV})^{11}$ had also been considered since the 2003 IWC/SC meeting (IWC, 2004) and was accounted for when reporting the estimates from SPLINTR and OK.

After 10 years of discussion and five intersessional workshops (IWC, 2004; 2009; 2010; 2012; 2013b), consolidated abundance estimates for CPII and CPIII were finally produced and adopted at the 2012 IWC/SC meeting. These were considered the best available abundance estimates in the survey areas for CPII and CPIII (IWC, 2013a). The estimates were based on the OK method, with some bias corrections for spatial effects using SPLINTR outputs (Table 2; IWC, 2013a). Two sets of estimates were provided: survey-once and CNB (Common Northern Boundary). The survey-once estimates cover all surveyed regions in each $\mathrm{CP}$ series. The $\mathrm{CNB}$ estimates excluded part of the surveyed regions in each series to ensure a consistent northern limit for the CPII and CPIII time periods. The CNB estimates are the most appropriate estimates for a comparison of abundance between CPII and CPIII and are the basis for the AV calculations. 'CV internal' in Table 2 shows the uncertainty associated with the abundance estimate for whales in the surveyed region at the time of the survey. ' $\mathrm{CV}$ with $\mathrm{AV}$ ' in Table 2 shows the uncertainty

\footnotetext{
${ }^{11}$ Additional variance is variance in addition to survey sampling variability, arising for example from wide scale distributional variations over time.
}

associated with the average number of whales present in the surveyed region across the whole of that $\mathrm{CP}$ series and is more appropriate for most subsequent analyses. Only one set of CVs is presented in Table 2 because these $\mathrm{CVs}$ are approximately the same for survey-once and CNB. A null hypothesis of no change in overall abundance between CPII and CPIII was not rejected because the ratio of total abundance in CPIII to CPII, formerly 0.47 with the standard method, was now estimated to be 0.69 with $95 \%$ CI [0.43, 1.13]. Although these estimates were considered the best available for the CPII and CPIII time period, they remain negatively biased because the presence of whales outside the northern and southern (i.e. within the sea ice) boundaries is ignored in their calculation. The data for CPI were not analysed using the new methods because no IO mode data were available from CPI, and these are needed to be able to take account of the extent to which $g(0)$ is less than 1 . Abundance estimates in Areas III-E, IV, V and VI-W, that were used in the Statistical Catch-at-Age Assessment (SCAA) described below under 'Population dynamics' (see below for details) are shown in Table 3.

\section{JARPA/JARPAII}

The JARPA and JARPAII abundance estimates focus on Areas III-E to VI-W. As with the analysis of the IDCR/ SOWER data, the analytical methods evolved over time, accounting for issues related to the data and as longer time series became available. Kishino et al. (1991) presented the first abundance estimates for each Area by school size based on the 1987/88 and 1988/89 JARPA data. Nishiwaki et al. (1997) presented abundance estimates for Areas IV and V based on the JARPA sighting surveys from 1989/90-1995/96 to an intersessional working group (IWC, 1998). This group recommended that the analytical method needed to account for the under-sampling of high-density areas (called the skip effect ${ }^{12}$ ) to produce a less negatively biased abundance estimate.

Two methods were presented at a 2006 intersessional workshop (IWC, 2008b), that accounted for the undersampling. Burt and Paxton (2006) presented a spatial

\footnotetext{
${ }^{12}$ The survey design specified fixed waypoints to be reached each day. In days where, for example, high densities and consequent examination of more frequent sightings resulted in a way-point not being reached, the vessel would 'skip' to that way-point overnight to start the survey from there the next day. This process introduces a bias because it introduces a tendency to relatively under-sample higher density regions.
}

Table 2

Agreed abundance estimates for CPII and CPIII in each IWC Management Area (IWC, 2013a). CNB: Common Northern Boundary. AV: Additional Variance. See text for explanation.

\begin{tabular}{ccccccccc}
\hline & & \multicolumn{7}{c}{ IWC Management Area } \\
\cline { 3 - 9 } CP & & I & II & III & IV & V & VI & Total \\
\hline \multirow{2}{*}{ II } & Survey once & 85,688 & 130,083 & 93,215 & 55,237 & 300,214 & 55,617 & 720,054 \\
& CNB & 84,978 & 120,025 & 86,804 & 51,241 & 285,559 & 49,885 & 678,493 \\
& CV internal & 0.16 & 0.14 & 0.2 & 0.17 & 0.13 & 0.22 & 0.08 \\
& CV with AV & 0.34 & 0.4 & 0.44 & 0.39 & 0.31 & 0.39 & 0.18 \\
\hline \multirow{2}{*}{ III } & Survey once & 38,930 & 57,206 & 94,219 & 59,677 & 183,915 & 80,835 & 514,783 \\
& CNB & 34,369 & 58,382 & 68,975 & 55,899 & 180,183 & 72,059 & 469,866 \\
& CV internal & 0.2 & 0.19 & 0.15 & 0.34 & 0.11 & 0.14 & 0.09 \\
& CV with AV & 0.39 & 0.38 & 0.35 & 0.49 & 0.36 & 0.37 & 0.18 \\
\hline
\end{tabular}


Table 3

Agreed abundance estimates for Antarctic minke whales in Areas III-E, V, $\mathrm{V}$ and VI-W based on the IDCR/SOWER CPII and CPIII data (IWC, 2013a). These estimates were used as input data to the SCAA population dynamics model.

\begin{tabular}{ccccrc}
\hline CP & Year & Area & Area size $($ n.mile & Abundance & CV \\
\hline II & 1986 & V-E & 553,315 & 154,658 & 0.19 \\
II & 1986 & V-W & 369,337 & 105,951 & 0.16 \\
II & 1988 & III-E & 216,439 & 11,782 & 0.44 \\
II & 1989 & IV & 473,477 & 46,763 & 0.17 \\
II & 1991 & VI-W & 311,778 & 20,438 & 0.27 \\
III & 1995 & III-E & 269,356 & 34,659 & 0.24 \\
III & 1996 & VI-W & 446,457 & 48,206 & 0.18 \\
III & 1997 & IV & 476,894 & 55,873 & 0.34 \\
III & 2002 & V-W & 349,951 & 43,640 & 0.14 \\
III & 2004 & V-E & 478,019 & 136,457 & 0.13 \\
\hline
\end{tabular}

modelling approach applied to the JARPA data, and Hakamada et al. (2006) presented updated abundance estimates based on the JARPA sighting data using the IWC 'standard' methodology and an inter-mode calibration method developed by Haw (1991). The workshop noted potential difficulties in correcting for skip effects by applying spatial models and agreed that the standard design-based estimates were best at that stage although requiring some corrections. Additional recommendations were made that related to improving the estimates of abundance, trends, and precision, and to incorporating factors that might potentially bias the abundance trend and variance estimates (IWC, 2008b).

Revised estimates of abundance and trends for Areas IV and V were obtained taking the 2006 workshop recommendations into account by Hakamada et al. (2013). Log-linear models were used to adjust for different strata being surveyed at different times of year over the duration of JARPA, with model selection being based on the corrected Akaike information criteria (AICc). IO mode had not been implemented during JARPA and thus $g(0)$ for the surveys could not be estimated. Instead, effects of changes in $g(0)$ over time were investigated for the JARPA abundance estimates using a regression model, developed from the results of the $\mathrm{OK}$ method applied to Antarctic minke whale data from the IDCR/SOWER surveys, which provided estimates of $g(0)$ for a distribution of minke whale school sizes.

At a 2014 review workshop (IWC, 2015c), the approach in Hakamada et al. (2013) was applied to JARPA and JARPAII data for Areas III-E, IV, V and VI-W between 1989/90 and 2008/09 (Hakamada and Matsuoka, 2014a). The resultant abundance estimates for Areas III-E, IV, V and VI-W, both accounting for and ignoring model error, are shown in Table 4. Within the time frame of JARPA and JARPAII, the estimated annual rates of increase in abundance were $1.1 \%$ with a $95 \%$ CI of $[-2.3 \%, 4.5 \%]$ for Area III-E + IV and $0.6 \%$ with a $95 \%$ CI of $[-2.2 \%, 3.3 \%$ ] for Area V + VI-W for the estimates that took the model error into consideration (Hakamada and Matsuoka, 2014a). Sensitivity analyses showed that the estimates were robust to effects related to potential biasing factors. The IWC/SC agreed that Hakamada and Matsuoka (2014a) adequately addressed most of its previous concerns (IWC, 2015c) and the relative abundance estimates in Table 4 were used in the
Table 4

Abundance estimates for Antarctic minke whales based on applying the approach in Hakamada et al. (2013) to JARPA and JARPAII data collected during 1989/90 - 2008/09 with (a) and without (b) taking model error into account (Hakamada et al., 2014a). Average is average of annual abundance estimates for each Area over years when the estimates are obtained. Minimum and maximum are minimum and maximum of the annual abundance estimates among the years for each Area, respectively. Model error is error due to other than sampling error. These estimates were used as input data to the SCAA population dynamics model.

\begin{tabular}{crrrrr}
\hline & Average & \multicolumn{2}{c}{ Minimum } & \multicolumn{2}{c}{ Maximum } \\
\cline { 2 - 6 } Area & Estimate & Estimate & CV & Estimate & CV \\
\hline (a) & & & & & \\
III-E & 18,759 & 4,478 & 0.911 & 48,540 & 0.711 \\
IV & 32,714 & 15,088 & 0.645 & 63,794 & 0.509 \\
V & 101,106 & 67,661 & 0.308 & 151,072 & 0.326 \\
VI-E & 15,486 & 8,434 & 0.601 & 27,790 & 0.507 \\
(b) & & & & & \\
III-E & 18,569 & 5,566 & 0.367 & 44,801 & 0.582 \\
IV & 32,474 & 14,739 & 0.570 & 62,979 & 0.334 \\
V & 114,550 & 69,771 & 0.228 & 170,621 & 0.129 \\
VI-E & 15,603 & 7,530 & 0.226 & 26,364 & 0.218 \\
\hline
\end{tabular}

SCAA described below under 'Population dynamics'. Like the IDCR/SOWER abundance estimates, the JARPA/ JARPAII estimates are negatively biased because whales outside the northern and southern (i.e. within the sea ice) boundaries were not accounted for.

Abundance within the sea ice

It has long been known that Antarctic minke whales are distributed in the sea ice (Ainley et al., 2007; Ensor, 1989; Naito, 1982; Ribic, et al., 1991; Taylor, 1957; Thiele and Gill, 1999) out of range of the IDCR/SOWER and JARPA/JARPAII surveys. In those surveys, the ice edge was defined by a level of ice cover that prevented the survey from being conducted at nominal survey speed of about 11.5 knots (Matsuoka et al., 2003a). Several unsuccessful attempts were made to estimate abundance to the south of the ice edge in Areas II, III, IV, V and VI during those surveys (Murase and Kitakado, 2013; Murase and Shimada, 2004a; Murase et al., 2005; Shimada and Burt, 2007; Shimada and Murase, 2002; 2003; Shimada et al., 2001; Shimada et al., 2002). Other attempts were made to investigate the magnitude of the potential abundance within the ice fields by describing the relationship between abundance and sea ice concentrations as derived from satellite data (Matsuoka et al., 2006; Matsuoka et al., 2008; Matsuoka et al., 2009; Murase and Shimada, 2004a, 2004b; Murase et al., 2011; Shimada and Murase, 2006). Although these studies demonstrated that a considerable number of Antarctic minke whales were in sea ice field, no agreed abundance estimates were produced because of the lack of sighting data in sea ice fields during the times that the IDCR/SOWER and JARPA/JARPAII surveys took place.

More recently, abundance within sea ice fields in portions of Area III $\left(40^{\circ}-50^{\circ} \mathrm{E}\right)$ and Area IV $\left(70^{\circ}-82^{\circ} \mathrm{E}\right)$ was estimated by using data from the Japanese icebreaker Shirase in 2004/2005 (Shimada and Kato, 2006; 2007). Abundance in sea ice fields in portions of Area IV $\left(93^{\circ}-110^{\circ} \mathrm{E}\right)$ was estimated using data from the Australian fixed wing aircraft surveys in 2008/2009 and 2009/2010 (Kelly et al., 2014). Abundance in sea ice fields in the Weddell Sea (part of Area 
II) was estimated using data from German helicopters in 2006/07 and 2008/09 (Williams et al., 2014). The Kelly et al. (2014) aerial surveys were corrected for perception bias (bias due to missing animals that were available to be detected but were missed due to factors such as sun glare). However, none of the aerial surveys were corrected for availability bias (bias due to missing animals that were not available to be detected because, for example, they were too deep below the surface and hence out of range of the visual observers). To obtain absolute abundance estimates using aerial survey data, corrections of perception and availability bias are both necessary, of which availability bias is more difficult to account for. The IWC/SC agreed that to account for availability bias, information is needed on the amount of time minke whales are below the surface (and thus undetectable) in a range of ice conditions, and on the level of visibility of minke whales from the air as a function of depth and water clarity (IWC, 2015b).

The Joint Symposium on High Latitude Sea Ice Environments was held before the $2005 \mathrm{IWC} / \mathrm{SC}$ annual meeting to review information on sea ice environments in the Arctic and Antarctic, and to develop ways to incorporate sea ice and similar data into analyses and models used by the IWC/SC in its work. This work includes abundance estimation, determining the associated variance, resolving issues of habitat use and the implications of seasonal, interannual and decadal variability in sea ice on cetacean populations and habitat (IWC, 2006). Methods and data for estimation of abundance in the sea ice field were evaluated by Kelly et al (2012), while technical aspects of sea ice data derived from satellites have been reviewed by Murase et al. (2012).

\section{Spatial distribution}

Prior to this IA, the spatial distribution of Antarctic minke whales in the Indo-Pacific sector was investigated qualitatively using either overlay maps (Ichii, 1990; Matsuoka et al., 2003b; Murase et al., 2002) or simple statistical correlations (e.g. Kasamatsu et al., 2000).

More recently, a spatial modelling approach (Murase, 2014) based on generalised additive models (GAMs) was developed using IDCR/SOWER data to model the spatial density (abundance) surface (Hedley et al., 1999). Murase (2014) considered as explanatory variables the following: position (longitude and latitude), geographical features (bathymetry and distance to the upper slope) and climatological data at the surface (water temperature, sea surface height, salinity, and chlorophyll, silicate, nitrate and oxygen concentrations). Preliminary results suggested that whilst Antarctic minke whales were found throughout the Indo-Pacific during both CPII and CPIII, the areal extent of regions of high density may have decreased (Fig. 8).

The relationship between the circumpolar spatial distribution of Antarctic minke whales and their environment was also investigated applying GAMs to CPI, II and III data sets (Beekmans et al., 2010), but maps of estimated spatial distribution were produced for the Weddell and Ross Sea regions only. A study using GAMs and JARPA data demonstrated that the spatial distribution of Antarctic minke whales in the Ross Sea was related to the spatial distribution of krill (Murase et al., 2013). Although this study showed that prey data could be used as a covariate of spatial models, it cannot be applied to IDCR/SOWER because prey data were not recorded concurrently in the surveys.

Some of the difficulties of trying to model relationships between environmental covariates and species distributions using methods such as GAMs include: (1) it is often best to exclude 'spatial' variables (such as latitude and longitude), and instead fit the spatial variables to model residuals when trying to model the effect of environmental covariates on species distributions; (2) model selection within GAMs is not straightforward; this is a developing statistical field in its own right; and (3) with relationships between species distributions and environmental covariates, it is unlikely that there will be several maxima and minima in species densities over the sampling space of the covariate, so that in a GAM context, it is preferable to constrain the degrees of freedoms to smooth out spurious peaks (IWC, 2015b). Improved spatial modelling approaches will enhance future in-depth assessments of Antarctic minke whales (and other species).

\section{BIOLOGICAL INFORMATION}

Several parameters such as the age at sexual maturity (tm50\%) and the growth curve estimated from commercial samples were known to be biased because whaling operation was mainly conducted in the ice-edge zone, where mature females segregate and selectivity of whalers for larger whales (Kato and Sakuramoto, 1991). On the other hand, JARPA was designed to cover a greater range of latitudes than commercial whaling and to collect samples randomly and systematically based on the line-transect method (Nishiwaki et al., 2006) and biological parameters were estimated by correcting for sampling rate in each stratum and school size. This method leads to less-biased samples compared to those based on the commercial catches, which lead to improved estimation of biological parameters.

\section{Age}

The age of baleen whales, including Antarctic minke whales has traditionally been estimated by counting growth layer groups (GLGs) accumulated in the earplug, assuming an annual deposition of growth layers i.e. one pair of dark and pale laminae per year (e.g. see Lockyer, 1984). Earplug age reading has been conducted from the start of exploitation in the 1970s and has been discussed since at least 1983 (IWC, 1984). Most recently, age reading error (i.e. the extent of bias and inter-reader variability among readers) was quantified by Kitakado et al. (2013), and this was then used in the SCAA (see the 'Population dynamics' section below for more details; Punt, 2014). In discussion about errors in ageing data using ages of Antarctic minke whale earplugs at the IWC/SC meeting, the age estimation approach based on aspartic acid racemisation (AAR) in eye lenses of bowhead (George et al., 1999) was suggested as a potential alternative approach that could be compared to the earplug approach (IWC, 2008a). The AAR approach was then applied to Antarctic minke whales and the results demonstrated it can complement the earplug approach, especially for young animals with unreadable earplugs (Yasunaga et al., 2017). 

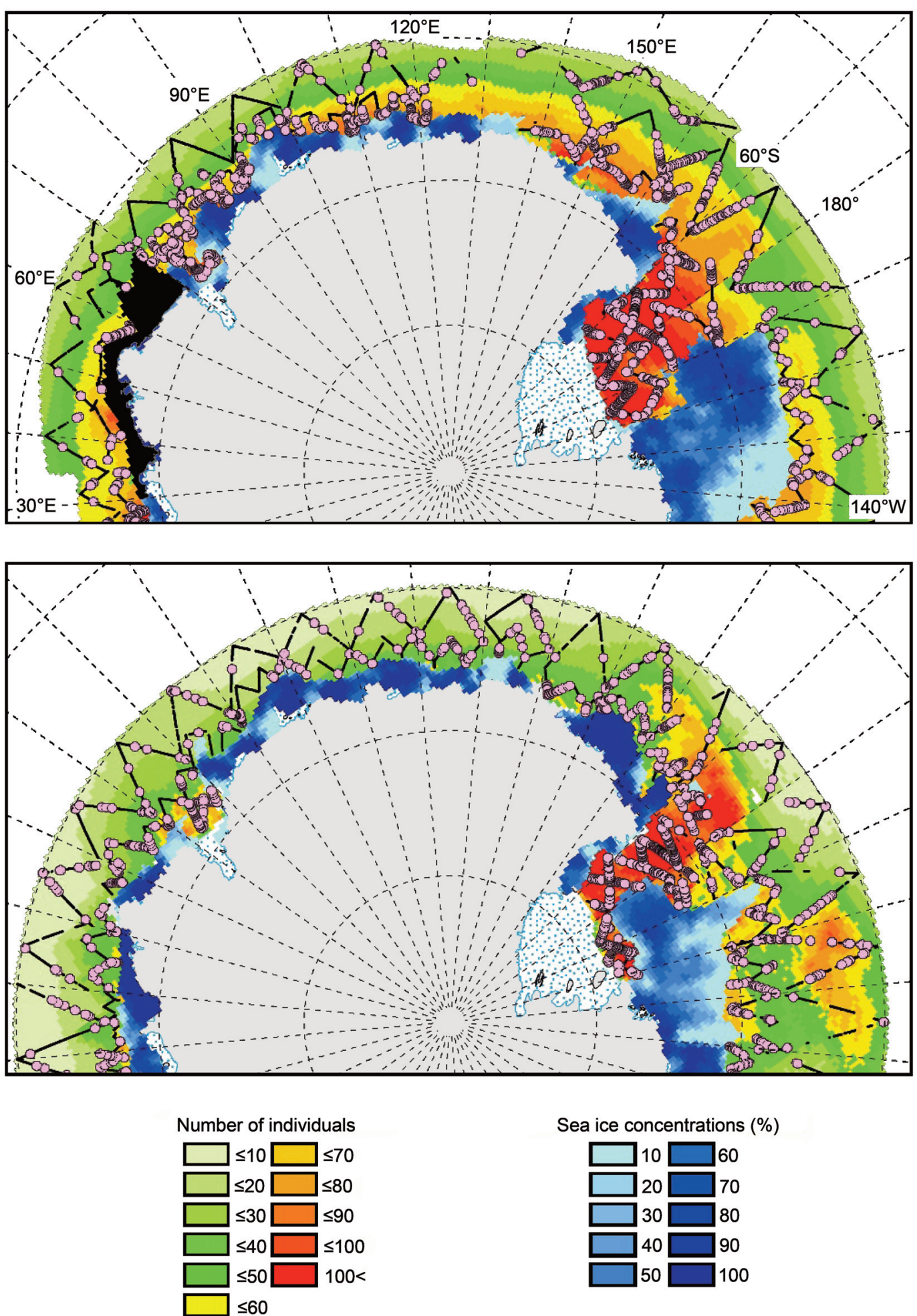

Fig. 8. Estimated spatial distribution (expressed in number of individuals) of Antarctic minke whales in the Indo-Pacific sector of CPII (top) and CPIII (bottom; redrawn from Murase, 2014). Sighting effort (black lines) and sighting positions of Antarctic minke whales (pink circles) are overlaid on the estimated spatial distribution map. Sea ice concentrations at the time of the surveys (from Murase et al., 2011) are also shown. Note that because satellite sea ice data are not available between $30^{\circ} \mathrm{E}$ and $70^{\circ} \mathrm{E}$ in CPII (top figure), the area is masked in black.

\section{Growth}

Growth curves for the I- and P-stocks were estimated by Bando et al. (2006b) using JARPA samples (Table 5). Mean body length increases rapidly until around age 7 and growth ceases at around 15-20 years of age. The estimated asymptotic length is about $20 \mathrm{~cm}$ larger in the I- than the P-stock: $8.63 \mathrm{~m}$ compared to $8.45 \mathrm{~m}$ for males, and $9.17 \mathrm{~m}$ compared to $8.93 \mathrm{~m}$ for females, respectively.
Physical maturity was determined based on the examination of the vertebral epiphysis of the 6th dorsal vertebra stained using $0.25 \%$ toluidine blue-O solution (Bando et al., 2006b). The cartilage between the epiphyses and the centrum was observed by naked eye or a stereoscopic microscope, and whales for which the epiphyses were fused to the centrum were considered to be physically mature. The estimated age at $50 \%$ physical maturity (i.e. age at 
Table 5

Summary of estimates of the values of biological parameters for Antarctic minke whales by stock (Bando et al., 2006b). Lmov: length of females at first ovulation, $L m 50 \%$ : length at which $50 \%$ of animals attained sexual maturity, tmov: Mean age of females at first ovulation, and tm50\%: Age at which $50 \%$ of animals attained sexual maturity.

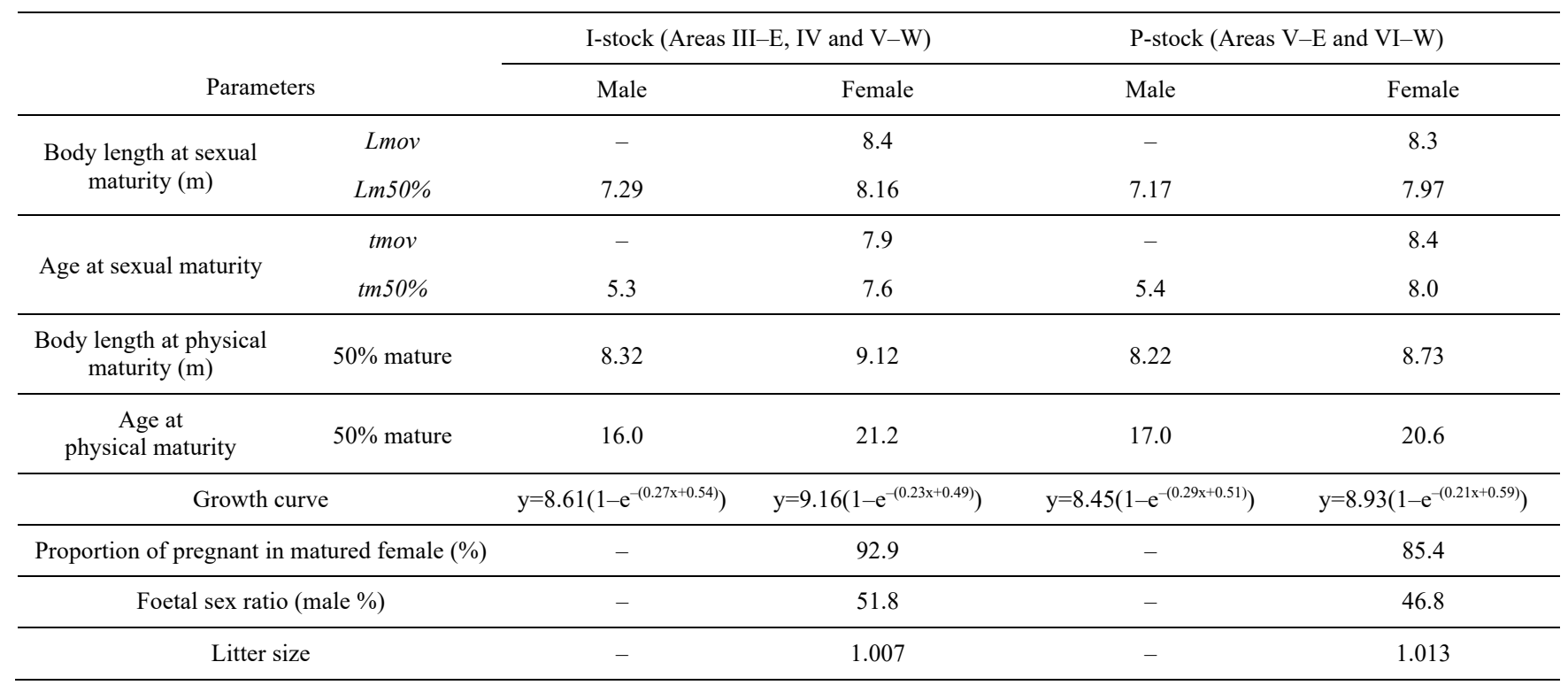

which $50 \%$ of animals attained physical maturity) occurred earlier in males for both stocks (Table 5). As in the case of asymptotic length, the body length at $50 \%$ physical maturity of the I-stock was larger than of the P-stock (Table 5).

\section{Sexual maturity}

Sexual maturity of males was determined by histological analyses of testes. Sexual maturity for females was determined by the presence of corpora luteum or albicans in the ovaries. Three methods have been developed to estimate the age and body length at sexual maturity of Antarctic minke whales (e.g. Kato, 1987).

(1) $t m 50 \% / L m 50 \%$ : Age/length at which $50 \%$ of animals attained sexual maturity;

(2) tmov/Lmov: Mean age/length of females at first ovulation; and

(3) tmp: Mean age estimated from the transition phase in the earplug.

The $t m 50 \% / L m 50 \%$ and tmov/Lmov were estimated using JARPA samples (Table 5; Bando et al., 2006b). The estimated body length at sexual maturity of I-stock whales was 10 $20 \mathrm{~cm}$ larger than P-stock whales for both sexes. The estimates of tmp by cohort have been examined by several authors by using commercial whaling and JARPA samples (Kato and Sakuramoto, 1991; Thomson et al., 1999; Zenitani and Kato, 2006; Bando et al., 2014). These studies demonstrated that the tmp declined from 14 years in the 1940 s to 7 years in 1960 s and then remained constant at 7-8 years until the 1990s cohorts, which were the latest cohorts estimated by this method. Further analyses using the approach of Thomson et al. (1999) to better account $\mathrm{f}$ or truncation bias and the fringe effect was recommended by the Expert Panel of JARPAII review meeting (IWC, 2015c).

\section{Reproduction}

Bando et al. (2006b) reported several biological parameters related to reproduction estimated using JARPA samples (Table 5). The proportion of pregnant mature females was estimated as $92.9 \%$ and $85.4 \%$ for the I- and P-stocks, respectively. It remained high during the JARPAII period and no significant trend was detected for either stock (Bando and Hakamada, 2014). The annual ovulation rate, which is the maximum value for the true pregnancy rate, was 0.98 and 1.01 for the I- and P-stocks, respectively, which indicates a high true pregnancy rate for Antarctic minke whales (Bando et al., 2006b). The foetal male ratio was $51.8 \%$ and $46.8 \%$ for the I- and P-stocks respectively, but neither differs statistically from parity $\left(\chi^{2}\right.$-test, $p=0.239$ and 0.091 for the I- and P-stocks, respectively). Multiple foetuses were rare, with only eight and nine twins amongst the 1,142 and 717 whales observed for the I- and P-stocks, respectively (Bando et al., 2006b).

The JARPAII Panel (IWC, 2015c) recognised that identification of lactating females is difficult in Antarctic minke whales because births occur in winter and lactation lasts only about three months, while sampling takes place in the summer i.e. some months after weaning. The Panel recommended that the feasibility of using histological examination of mammary glands to assess recent lactation be examined. If this is possible, the proportions of recently lactated to apparently pregnant females and to mature females could be a more appropriate index of reproductive success that would likely be more sensitive to environmental fluctuations than crude pregnancy rates because perinatal mortality or abandonments of newborns by females in low nutritive condition is known to occur in many mammal species.

\section{Natural mortality coefficient}

Natural mortality coefficients for the I- and P-stocks were estimated by Tanaka et al. (2006) using JARPA samples, by 
modifying the original method proposed by Tanaka (1990). Net rate of natural increase by stock was estimated by maximum likelihood. Using the zero increase rate of stock size from the statistical model selected using AICc, the point estimates of natural mortality for age classes over ten years old were $0.038 \mathrm{yr}^{-1}(\mathrm{SE}=0.036)$ for the I-stock and $0.040 \mathrm{yr}$ ${ }^{1}(\mathrm{SE}=0.035)$ for the P-stock.

\section{POPULATION DYNAMICS}

The data for Antarctic minke whales have been analysed using population dynamics models for over 40 years, although the focus for population dynamics research has changed over time (Punt, 2014). The earliest analyses aimed to provide a basis for setting catch limits, and to explore whether the extensive exploitation of other baleen whale species had led to the creation of a 'krill surplus' (e.g. see Laws, 1977) and hence whether Antarctic minke whales were increasing prior to the start of their more substantial exploitation in the early 1970s. A subsequent set of analyses also aimed to assess whether population dynamics models, along with data collected by JARPA could allow estimation of age-dependence in natural mortality $(M)$, as inferences regarding changes over time in minke whale abundance are sensitive to assumptions regarding the value for $M$ (fig 1 . of Punt, 2014). The most recent analyses have focused on directly estimating changes over time in carrying capacity and recruitment, and over age in natural mortality, and hence on exploring the possibility that the recent decline in recruitment is related to competition and other population dynamic-related factors (IWC, 2005).

As noted above, initial population models based on cohort analysis (e.g. Sakuramoto and Tanaka, 1985; 1986) were applied to data for Areas III and IV, treating the data for each Area separately. Subsequent ADAPT-VPA (Gavaris, 1988) analyses considered the Antarctic minke whales in Areas IV and V as separate populations (Butterworth and Punt, 1990; Bergh et al., 1991a; 1991b; Butterworth et al., 1996, 1999, 2002; Mori et al., 2007). However, the assumption that each Area contains a separate stock was shown to be untenable as discussed under 'Stock structure' above. This led to the development of population dynamics models based on SCAA that can simultaneously model multiple stocks (e.g. Punt and Polacheck, 2005, 2006; Punt et al., 2014), and extension of the area assessed from Areas IV and V to Areas III-E, IV, V and VI-W. However, even the most recent assessments have yet to allow for mixing of stocks in the assessed area, despite evidence that such variation occurs (Kitakado et al., 2014b). The VPA and SCAA were modified over time in response to review by the Scientific Committee. Thus, the following sections focus on the 'final' versions of the two methods (Butterworth et al., 2002 and Punt et al., 2014, respectively).

\section{Virtual Population Analysis (VPA)}

In common with all VPA-type methods, the VPA developed for Antarctic minke whales assumed that the catches-at-age were measured without error and projected cohort numbers backwards from either the most recent year or the oldest age. Initially, the VPA analyses were based on grouping and analysing the catch-at-age data on a 3-age-3-year basis to overcome small sample size problems for the statistical distribution underlying the estimator used at that stage, although subsequently analyses were also conducted on a 1-age-1-year basis. The analyses by Butterworth et al. (2002) followed the approach of Butterworth et al. (1999) and estimated age-dependent natural mortality, a fishing mortality scalar for the last year for which data were available (2001 for Area IV and 1998 for Area IV) and selectivity for the JARPA surveys and the commercial catches. The VPA was fitted to the JARPA indices of relative abundance, the IDCR estimates (taken to relate to absolute abundance) and the commercial and scientific catches-at-age.

The estimates of recruitment (and hence 1+ abundance) were estimated using the VPA to have increased over time (from at least the 1940s), to have peaked at the end of the 1960s and to have then declined and stabilised (Fig. 9). This result was robust to whether the model was based on a 1-age-1-year or 3-age-3-year basis, as well as to the choice of the plus-group for the catch-at-age data component of the likelihood function. The estimates of (age-independent) natural mortality were $0.07 \mathrm{yr}^{-1}(90 \%$ CI $0.036-0.093)$ and $0.049 \mathrm{yr}^{-1}$ (90\% CI 0.011-0.095) for Areas IV and V). However, the Scientific Committee did not adopt these estimates because it could not reach agreement on the validity of the selectivity assumptions on which the VPA was based (IWC, 1999).

In reviewing the results of the VPA, IWC (2005) noted that while population modelling could provide a way to address the plausibility of the hypothesis that the decline in recruitment is related to competition and other population dynamic-related factors, it considered that a SCAA modelling approach would provide the most appropriate way to address the population dynamics-related issues because a SCAA could allow inter alia for errors in catch-at-age data, more than a single stock, environmental covariates, fleet-specific vulnerabilities and changes over time in vulnerabilities to be addressed and explored within a single model framework.

\section{Statistical Catch-at-Age Analysis (SCAA)}

SCAA (Fournier and Archibald, 1982) involves developing a population dynamics model and fitting it to the available data by maximising an objective function. Punt and Polacheck (2005) noted that there were several potential concerns with the VPA approach as implemented at that time that could be addressed within the context of SCAA:

(1) the catch age-composition data were assumed to be known exactly when constructing the numbers-at-age matrix;

(2) it was not possible to estimate the numbers-at-age for some of the oldest ages in the earliest years for which commercial age-composition data were available directly using back-projection; and

(3) one of the key objectives of the past assessments of minke whales in Areas IV and V was to estimate the Maximum Sustainable Yield rate (MSYR), but the VPA could not do this directly.

The most recent version of the SCAA agreed by the IWC/SC (Punt et al., 2014) is sex-specific, can model 

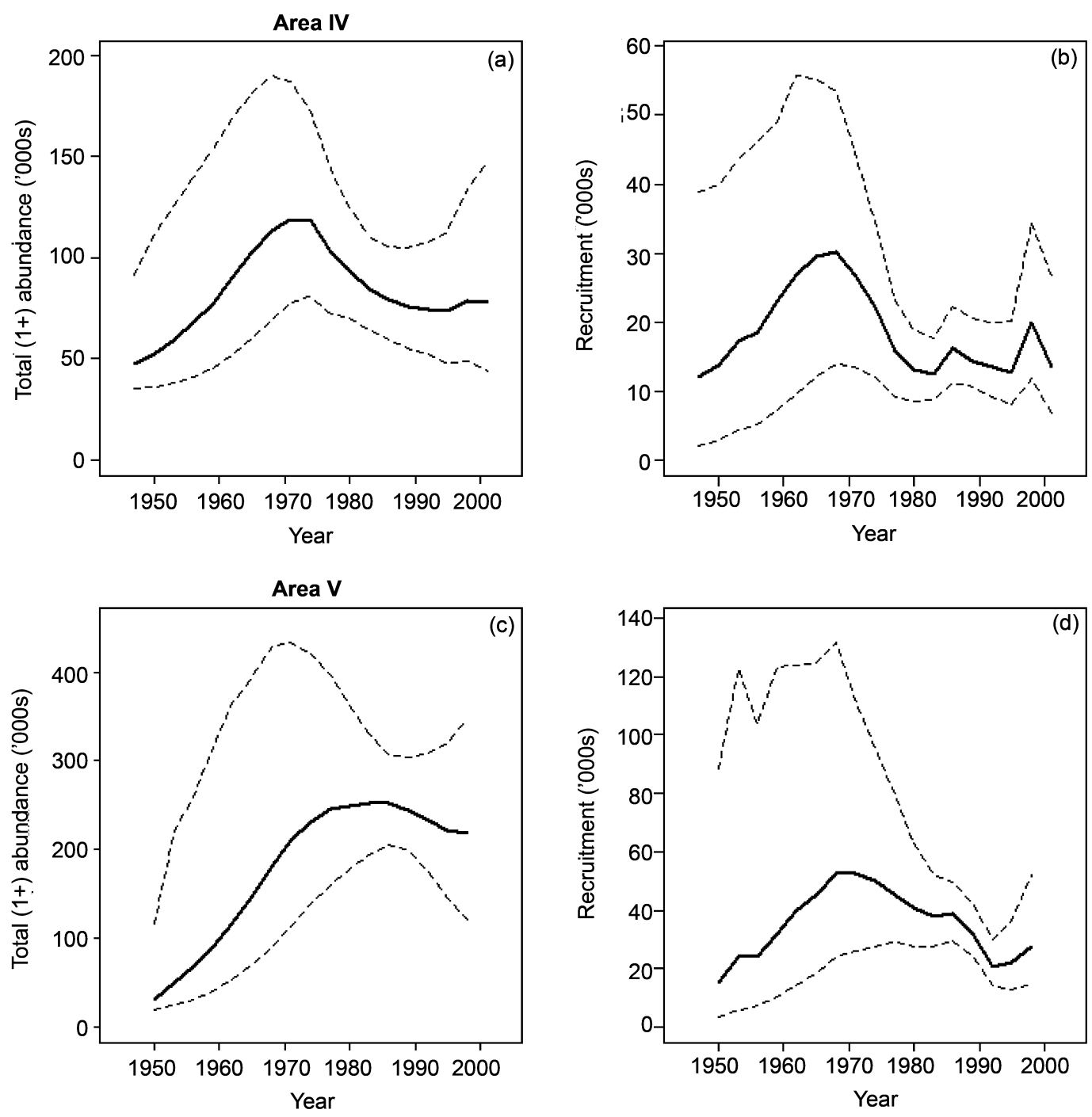

Fig. 9. Bootstrap estimates of total (1+) population size and recruitment for minke whales in Antarctic Areas IV and V based on the VPA, shown as medians together with estimates of 95\% CI's (reproduced from Butterworth, 2002).

multiple stocks simultaneously and allows for multiple fleets and regions. Furthermore, it permits changes over time in carrying capacity, deviations in calf numbers about the expected number of births, the growth curve, vulnerability and the proportion of each stock in each region. It includes multiple options for modelling the age-dependence in natural mortality, and sex- and length-specific vulnerability. The model allows some of its parameters (such as those related to the age-dependence of natural mortality and the resilience of the stock-recruitment relationship) to have values that are common among stocks. The model can be fitted to estimates of absolute and relative abundance, catch length-composition data and conditional age-at-length data. It is nominally fitted to the total catches by sex, but given the weight assigned to the associated likelihood component, the fit is almost exact. The objective function minimised includes the likelihoods for each data type and penalties on time-variation in births, vulnerability, growth, carrying capacity and area-proportion deviations.

The IWC/SC application to Antarctic minke whales assumes that there are two stocks in Areas III-E to IV-W, with the I-stock assumed to be found in Areas III-E, IV and $\mathrm{V}-\mathrm{W}$, and the P-stock assumed to be found in Areas V-E and
VI-W. The model includes 15 'fleets', consisting of three whaling types (Japan before 1987/88, Japan from 1987/88 and former USSR) in each of the five areas considered in the model. Two Japanese whaling types are considered so that the data for commercial and Scientific Permit catches can be treated separately, as the latter include more smaller whales. The SCAA ignored the length-frequency data for the former Soviet Union fleet because of concerns regarding the reliability of these data (there are no age-composition data for this fleet) and vulnerability for the former Soviet Union and the Japanese fleet were assumed to be the same. This latter assumption was made given information on possible misreporting of catch length distributions by the former Soviet Union (IWC, 2011).

The SCAA was based on a 'reference case' set of specifications, and a large number of sensitivity tests that involved making changes the specifications of the reference case to explore the implications of uncertainty and alternative choices for some of the functional forms and how the data are weighted (table 4 of Punt et al. 2014). The SCAA was able to mimic the available data well, although this was due in part to the large number of parameters and the allowance for both overdispersion and age reading error. The 
results from the SCAA analysis for the I- and P-stocks (with data until the 2012/13 austral summer) were qualitatively similar to those from the VPA for Areas IV and V (Figs 9 and 10). More specifically, the SCAA indicated that Antarctic minke whales in the region considered increased from 1930 until the mid-1970s, and then declined over the period from the mid-1970s until the late-1980s and have been stable thereafter. The estimated increase rate for total abundance from 1945 to 1968 was $1.9 \%$ (SE $0.7 \%$ ) annually for the I-stock and 2.1\% (SE 1.1\%) for the P-stock. Although the I- and P-stocks do not match Antarctic Areas IV and V exactly (and the assumption that Areas IV and V contain separate stocks is untenable anyway), the results from the SCAA are more precise (as might be expected given the longer time series available for analysis) and the recent trend for P-stock exhibits a continuing decline compared to the VPA. The initial increase in abundance was estimated to be due primarily to an increase in recruitment as a result of an increase in carrying capacity. However, carrying capacity was estimated to have declined following a peak for both stocks, but the effect of this on recruitment and hence total population size was much smaller for the P-stock than for the I-stock. The estimates of the recruitment (lower panels of Fig. 10) suggest that there have been periods of both good and poor recruitment. The early and peak abundances have higher CVs than recent abundance (fig. 4 of Punt et al., 2014).

Natural mortality is estimated in the form of a piecewise linear function of age (Fig. 11). The estimates of natural mortality indicate that it is highest for the youngest and (particularly) the oldest animals, with the estimate of natural mortality for age 15 of $0.048 \mathrm{yr}^{-1}$ (SE 0.005 ) for the I-stock and $0.046 \mathrm{yr}^{-1}$ (SE 0.005) for the P-stock, lower than the estimates from the VPA (Fig. 11).

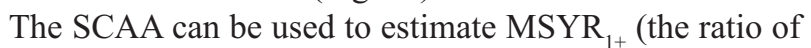
MSY to the total number of animals age 1 and older). The reference case SCAA estimates of MSYR ${ }_{1+}$ were generally very high $(>0.2)$, but some of the sensitivity tests led to estimates of $\mathrm{MSYR}_{1+}$ that are essentially zero. A primary reason for the inability to estimate $\mathrm{MSYR}_{1+}$ is that the stocks are estimated to have been close to carrying capacity throughout the modelled period for most of the SCAA analyses (fig. 3 of Punt et al., 2014).
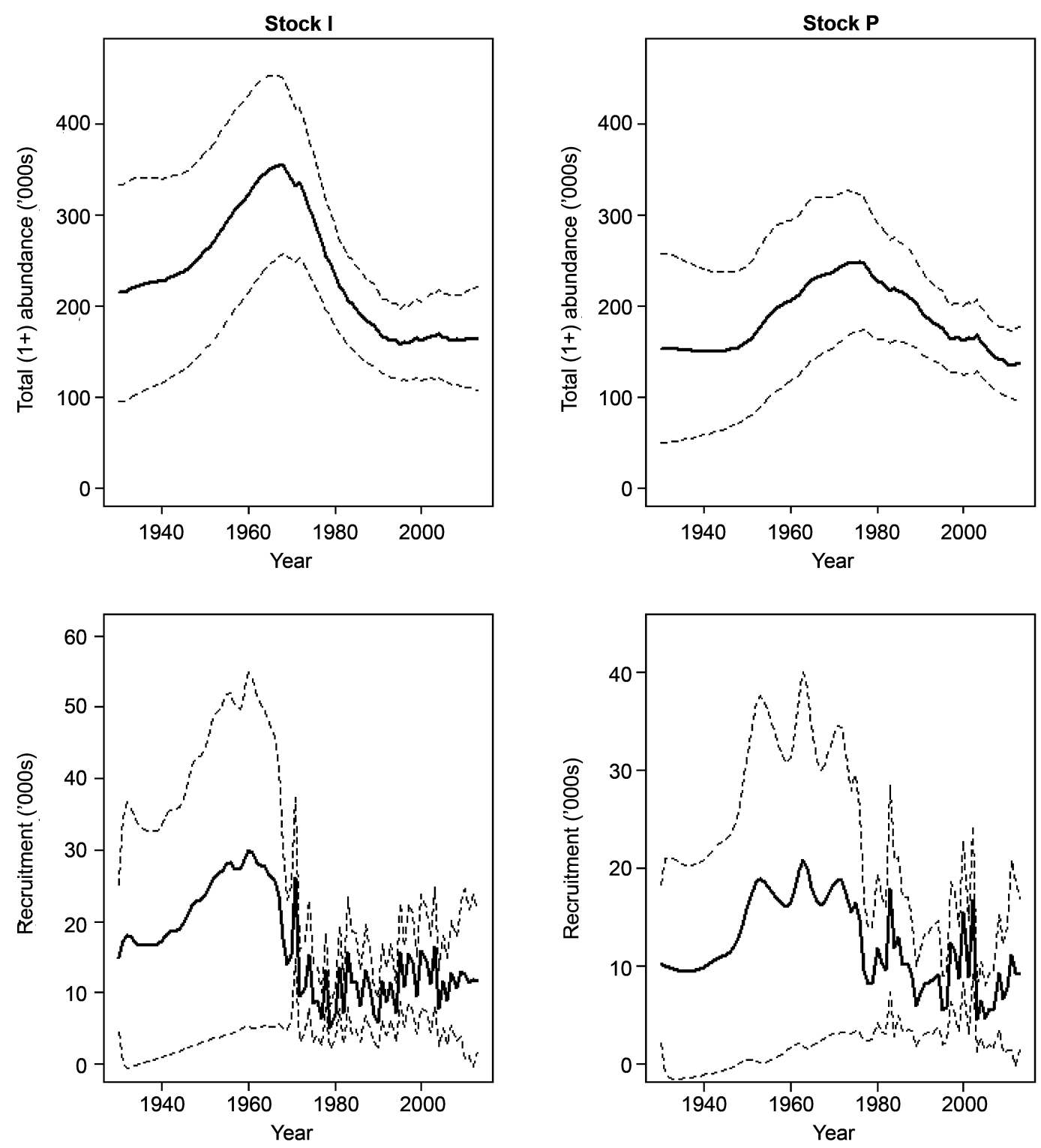

Fig. 10. Estimates of total $(1+)$ population size and recruitment for the I- and P-stock minke whales based on the SCAA. The dashed lines indicate $95 \%$ asymptotic confidence intervals. 

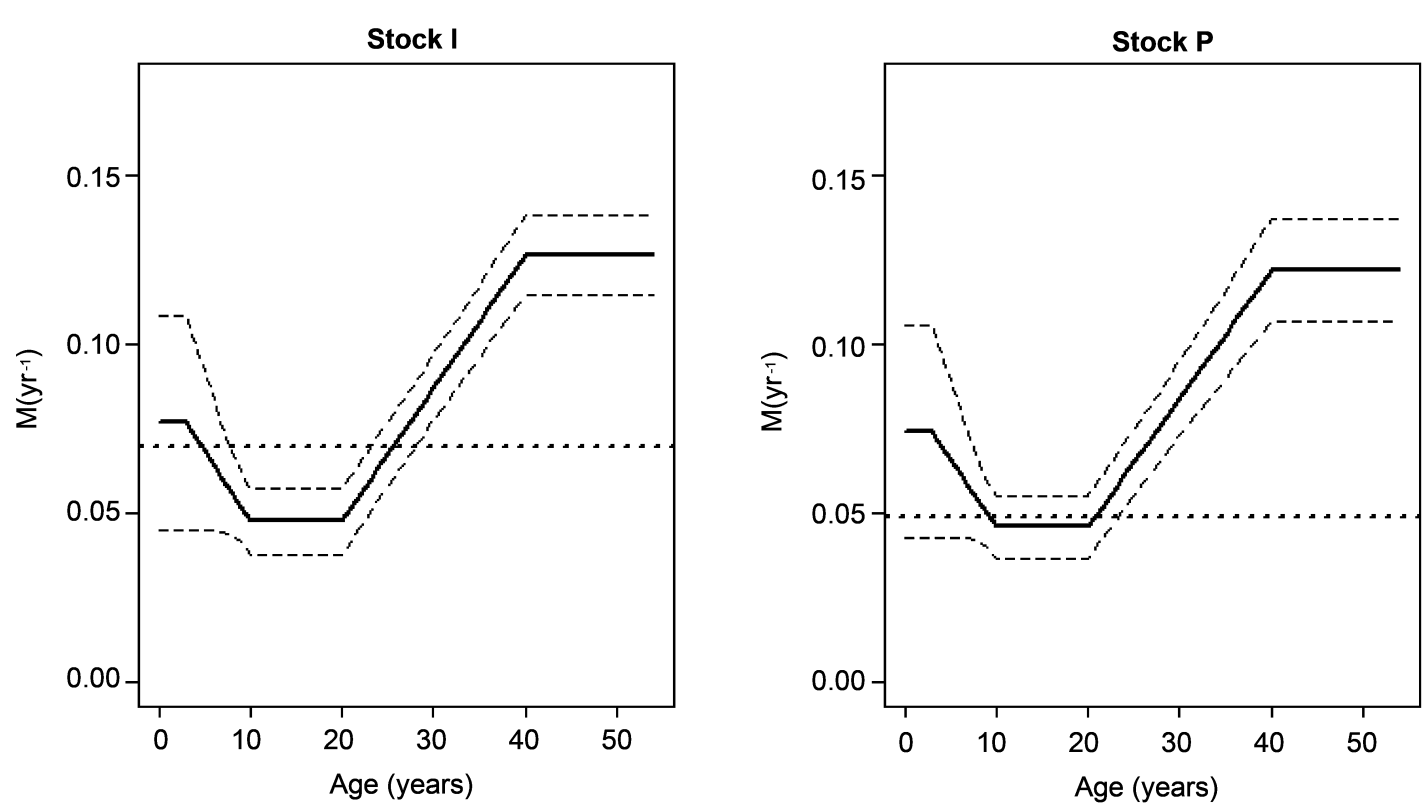

Fig. 11. Estimates of natural mortality for the I- and P-stock minke whales based on the SCAA. The dashed lines indicate $95 \%$ asymptotic confidence intervals. The horizontal dotted lines are the estimates of natural mortality from the VPA for Antarctic Areas IV and V.

The results are generally insensitive to changes to specifications of the SCAA reference case analysis. However, not allowing for time-varying growth leads to a markedly faster estimated rate of increase for the P-stock and also to higher estimates of natural mortality for very young animals for both stocks, while the rate of increase was lower over the initial years of the projection period when carrying capacity was assumed to be constant.

An original aim for developing the SCAA was to determine the reason or reasons for the decline in abundance of Antarctic minke whales between CPII and CPIII. The SCAA does not provide definitive conclusions in that regard. However, the results point to the possibility that carrying capacity has changed over time (first increasing then decreasing). Note that 'carrying capacity' in the model relates to trends in at least four processes: pregnancy rates, infant survival rates, age- 0 survival rates and changes in maturity - the data included in the SCAA do not allow these processes to be distinguished.

\section{Next steps}

Although this SCAA-based assessment was under development for almost a decade and had been refined through the suggestions and advice of the IWC/SC, there remain areas for future work as highlighted by Punt et al. (2014), including:

(1) consideration of other stock structure hypotheses, including a soft boundary in the Areas IV-E and V-W region, which depends on year and sex (Kitakado et al., 2014b);

(2) evaluation of the performance of the estimation method using simulations;

(3) application of the model to a broader range of areas within the Antarctic; and

(4) analysing the estimates of deviations in calf survival rate to identify the likelihood of possible causal mechanisms for the changes in recruitment over time.

\section{REAL DECLINE PLAUSIBLE HYPOTHESIS INVESTIGATIONS}

Amongst the list of plausible hypotheses to explain the apparent decline in abundance of Antarctic minke whales from CPII to CPIII were factors related to a real decline (IWC, 2003b), including: there may have been (1) an increase in natural mortality by killer whales; (2) a decrease in carrying capacity due to an increase in competition from predators; and (3) an increase in mortality due to pollutants and/or marine debris. These hypotheses were explored using a variety of data and methods.

\section{Killer whale hypothesis}

Anecdotally, the killer whale hypothesis was supported by Pitman and Ensor (2003) who documented that killer whales feed on Antarctic minke whales. However, the IWC/SC concluded that predation by killer whales was likely not a major reason for a decline in abundance of Antarctic minke whales when considering the estimated consumption rate of killer whales and their estimated abundance (Branch and Williams, 2003).

\section{Competition hypothesis}

The competition hypothesis was suggested because it appeared that the abundance of large baleen whales (southern right, fin, sei and humpback whales) in Areas IV and V-W increased, and their distributions expanded throughout the Areas at about the same time that the estimates of Antarctic minke whale abundance decreased from CPII to CPIII and their distribution shrank towards the southern ice edge. To address this hypothesis sighting data were investigated, minke whale consumption was estimated, total krill biomass was estimated, change in body condition was estimated and multi-species models were developed.

\section{Sightings data}

The information to explore these patterns were quantified in Branch (2007; 2011), Hakamada and Matsuoka (2014b), 
Matsuoka et al. (2005) and Matsuoka and Hakamada (2014). These general changes in patterns were evident in the IDCR/SOWER CPII and CPIII data (Murase, 2014) and in the JARPA/JARPAII data (Murase et al., 2014). Improvement of the associated models was recommended before it was possible to reach final conclusions (e.g. IWC, 2015b; c).

\section{Food habits and consumption}

Food habits and consumption estimates are fundamental pieces of data needed to address the competition hypothesis. In common with other balaenopterid species (except the Bryde's whale), the Antarctic minke whale spends its breeding season at lower latitudes in the austral winter and migrates to the Southern Ocean to feed in the austral summer (Horwood, 1990; Kasamatsu et al., 1995). These whales feed mainly on Antarctic krill (Euphausia superba) in offshore waters (Kawamura, 1980; Bushuev, 1986; Ichii and Kato, 1991), and on ice krill (E. crystallorophias) on the coastal shelf, in such areas as the Ross Sea and Prydz Bay (Bushuev, 1986; Tamura and Konishi, 2009). Previous studies have estimated the daily prey consumption by Antarctic minke whales in the Southern Ocean based on energy-requirement calculations (Lockyer, 1981; Armstrong and Siegfried, 1991; Reilly et al., 2004).

Based on data obtained by JARPA from 1987/88 to $2004 / 05$ seasons, the daily prey consumption was estimated using two independent methods, which were from theoretical energy requirement calculations and from diurnal changes of stomach contents' mass. The daily prey consumptions of Antarctic minke whales per capita during the feeding season based on these two methods were 95.1-127.0 and 182.6$250.3 \mathrm{~kg}$ for immature and mature males, and $125.8-138.7$ and $268.1-325.5 \mathrm{~kg}$ for immature and mature females, respectively. These values are equivalent to $2.65-4.02 \%$ of body weight. The seasonal prey consumption by Antarctic minke whales was 3.58-4.05million tonnes, and that this amounted to $7.7-8.7 \%$ of the krill biomass estimated by acoustic surveys in Areas III East, IV, V and VI West combined (Tamura and Konishi, 2014).

The JARPAII Review Panel pointed out that the krill biomass estimated by JARPA acoustic surveys required additional work to ensure the classification of acoustic targets and resulting biomass estimates were correct (IWC, 2015c). The Panel also highlighted that the data from the JARPA programs alone are limited and recommended JARPA scientists collaborate with other researchers conducting Antarctic krill surveys. In addition, the Panel noted that the prey consumption results presented did not quantify uncertainties in the various estimates of consumption and therefore, the Panel was unable to determine whether JARPA and JARPAII had provided or will provide consumption estimates within a sufficiently narrow range (IWC, 2015c).

Estimation of the uncertainty associated with estimating the amounts and types of prey consumed by whales was assisted by reviews by Leaper and Lavigne (2007) and Tamura et al. (2009). These uncertainties (e.g. allometric relationships, body weight of whales, energy values of prey species, assimilation efficiency and length of feeding period) were quantified using Monte Carlo methods (IWC, 2015c) and could be used in future ecosystem models and assessments.

\section{Change in body condition}

A potential indicator of a change in carrying capacity is a change in body condition. Whales generally accumulate energy as lipid in the blubber during the summer feeding period at high latitudes and as they migrate to low latitude areas (Næss et al., 1998), spending the energy for reproduction and migration. The proxy of fat reserves in blubber has been used as an indicator of body condition in many whale studies (e.g. Christiansen et al., 2013; Haug et al., 2002; Ichii et al., 1998; Lockyer, 1986; Lockyer et al., 1985). Blubber thicknesses, blubber weight and girth have been used as the indices in previous studies and found to increase through the feeding season (Christiansen et al., 2013; Konishi et al., 2008; Lockyer, 1987; Næss et al., 1998). In fact, the measurements of blubber thickness correlate positively with lipid content in blubber tissue and have proven to be a dependable proxy for energy storage in whales (Lockyer et al. 1985).

Multispecies models could address this hypothesis (IWC $2003 \mathrm{~b}$ ), and the estimates of trends in body condition would ultimately be important to consider in fitting multi-species models (IWC, 2015a). Annual trends in energy storage in Antarctic minke whales using JARPA data were published by Konishi et al. (2008), showing that blubber thickness, girth and fat weight had been decreasing during the JARPA period. The decrease per year is estimated at approximately $0.02 \mathrm{~cm}$ for mid-lateral blubber thickness and $17 \mathrm{~kg}$ for fat weight, corresponding to $9 \%$ for both measurements over the 18-year period (Konishi et al., 2008). This conclusion was questioned since the 2011 IWC/SC because sampling heterogeneity in JARPA and interannual variability of body condition make conclusions regarding statistical significance questionable (de la Mare 2011; 2012; de la Mare et al. 2014). After the IWC/SC discussions, the JARPAII Review Panel recommended that a conceptual model of the system under consideration be developed and used to identify a set of covariates to consider in the modelling with following model selection steps (IWC 2015c):

(1) identify whether any of the covariates are highly correlated and either (a) exclude a subset of the covariates so that the remaining covariates are uncorrelated or (b) develop new covariates which represent independent aspects of the current covariates (using for example PCA);

(2) select a 'full model' (this may be difficult if the data set is unbalanced) and base selection of which factors and their interactions to treat as random effects - the models should be fitted using REML and a model selection approach such AIC, BIC or standard hypothesis testing approach applied;

(3) select the fixed effects structure given the random effects structure selected at step (2), where the models are fitted using maximum likelihood; and

(4) use REML to fit the best model identified in (3) above. 
During the $2014 \mathrm{IWC} / \mathrm{SC}$, the analyses based on the recommendations had been satisfactory completed, and the IWC/SC agreed that a decline in blubber thickness and in fat weight had occurred during the JARPA period and was statistically significant at the 5\% level (IWC, 2015a; Konishi and Walløe 2015). In this regression analyses, the covariates in a full model consisted of sex, body length, date, diatom adhesion level, latitude, longitude and longitudinal sector, and random effects for date by longitudinal sector, latitudinal zone, track line, distance to ice edge and random effects for year were tested.

\section{Modelling}

Attempts were made to construct multi-species ecosystem models to investigate indirect competition ${ }^{13}$. Mori and Butterworth (2004) constructed a multi-species production model of the interactions among krill, Antarctic minke and blue whales at a circumpolar scale. Additional species (fin and humpback whales, and Antarctic fur and crabeater seals) were included in an expanded model (Mori and Butterworth, 2006) of the Indian and Atlantic sector (Areas II, III and IV) and the Pacific sector (Areas I, V and IV). Furthermore, a preliminary whole-ecosystem model for area IV using Ecopath has been attempted (Kitakado et al., 2014a). Development of an individual-based model (IBM; de la Mare, 2013) is in progress and foraging behaviour data obtained by multi-sensor digital archival tag (Friedlaender et al., 2014; 2016) could also be used in such a model. It was agreed that there is a critical need for species-specific, finescale data on cetacean feeding and prey to parameterise the IBM to study competition between baleen whales (IWC, 2015a).

\section{Summary}

In summary, while all these studies provide a useful starting point to investigate the competition hypothesis, additional data collection of the predators and prey and improved modelling analyses are required (IWC, 2015a). Therefore, no firm conclusions on species interactions were reached from these preliminary exercises during this IA.

\section{Chemical pollutant hypothesis}

One of the hypotheses for the appreciable difference in the abundance between CPII and CPIII is increased natural mortality due to increased pollutant levels. At the time the hypothesis was proposed the IWC/SC assumed that effect of pollutants would be negligible (IWC, 2003b). Pollutants were monitored by JARPA and JARPAII because the IWC/ $\mathrm{SC}$ established a regular agenda item for research on effects of environmental change on cetaceans in 1993 (IWC, 1994). The IWC/SC subsequently held a workshop on the relationship between chemical pollutants and cetaceans in Bergen in March 1995 (IWC, 1995b). This Workshop recommended that priority be given to carefully defined and

\footnotetext{
${ }^{13}$ Direct and indirect competitions are defined in the IWC/SC as follows: Direct competition occurs when two predators are present in the same area as a prey species and may interfere with each other's access to the prey. When the two predators occur in different parts of the area of prey distribution, indirect competition may occur because the prey's production is limited so that consumption by the one predator limits the production available for the other, and vice versa. (IWC, 2015a)
}

designed studies on species in highly polluted areas to assess whether they exhibit adverse effects and in unpolluted areas that may be used to infer baseline biological parameters or physiological 'normality' to examine cause-effect relationships between cetacean health and chemical pollutants. To address this recommendation, the objective 'Elucidation of the effect of environmental changes on cetaceans' was added to the 1995/96 research plan of JARPA (Government of Japan, 1995).

Yasunaga et al. (2015) reported to the JARPAII review meeting in 2014 that levels of PCBs, DDTs, HCHs, HCB and CHLs in blubber of minke whales taken by JARPA from Areas V and VI decreased extremely slowly over time, or were steady over time, while those of $\mathrm{HCHs}$ declined substantially. Levels of DDTs, HCHs, HCB and CHLs in Area V decreased significantly with year during the JARPA/ JARPAII period, while the yearly trend of PCBs did not change significantly. HCHs levels in minke whales in 2010/ 11 were similar to those from $1996 / 97$ to $2004 / 05$, but lower than those from 1988/89 to 1996/97 (Yasunaga et al., 2014a). These results suggest that levels of $\mathrm{HCHs}$ in the Antarctic Ocean have varied from decreasing slightly to being steady in the mid-1990s. Yasunaga et al. (2006) also reported that $\mathrm{Hg}$ intake in young minke whales (1-15 years) decreased significantly with sampling year, while that of individuals over 16 years was stable, and Yasunaga et al. (2014b) used samples taken by JARPA and JARPAII until 2013 to report that hepatic $\mathrm{Hg}$ levels of minke whales of all age groups in Area IV decreased significantly within the year, whereas that for the 15-26 year old whales in Area V increased significantly, possibly indicating that food availability of Antarctic minke whales in 2000s may have differed from those in 1980s and 1990s.

In summary, the 2014 JARPAII Review Panel concurred that the results indicating very low organochlorines and mercury levels observed in tissues of Antarctic minke whales throughout the period of JARPA and JARPAII pointed towards a lack of effects on whale populations (IWC, 2015c). The Panel recommended that pollution studies should be given lower priority and the resources used to address other higher priority issues if the programme continues.

\section{Marine debris hypothesis}

Another hypothesis for the appreciable difference in abundance between CPII and CPIII was increased mortality due to marine debris, which could cause disease or be ingested and lead to starvation. The size of effect was considered unknown (IWC, 2003b). In 2013 a workshop on marine debris agreed that marine debris, and its contributions to entanglement, exposures including ingestion, and associated impacts, including toxicity, is both a welfare and a conservation issue for cetaceans on a global scale (IWC, 2014).

Sightings of floating macro debris were recorded from the JARPA/JARPAII vessels during $1987 / 88$ to $2010 / 11$, and plastics from the stomach contents and entanglement in Antarctic minke whales were recorded (Isoda et al., 2014). Buoys made of plastic were most abundant ( $69 \%$ of all debris recorded) throughout Areas III-E, IV, V and VI-W, with the highest density observed in Area V (DI $=0.15)$ (DI: number of marine debris observed per $100 \mathrm{n}$. miles), followed by Area IV (DI: 0.12). The density in Areas IV and V increased 
rapidly after 2005/06. Although licensed longline vessels started fishing in $2004 / 05$, the operation by IUU (illegal, unreported and unregulated) vessels have been reported in this area (SC-CAMLR, 2011).

Similar patterns of marine debris occurrence were reported in the sightings data collected during the IDCR/SOWER surveys. In Area III-E, only one and two floating macro debris were found during CPII (1987/88) and CPIII (1994/ 95) respectively. In Area IV, there were three and 17 floating macro debris were found in CPII (1988/89) in CPIII (1998/99) respectively. In Area V, 16 and 37 sightings in CPIII (1991/92) and in CPIII (2001/02, 2002/03 and 2003/04). In Area VI-W, there was one sighting in CPII (1990/91) and eight sightings in CPIII (1995/96) (Joyce et al., 1988; Kasamatsu et al., 1989; Joyce et al., 1991; Ensor et al., 1992; 1995; 1996; 1999; 2002; 2003; 2004.

From the stomach contents records collected in JARPA/ JARPAII, ingested plastic items (one plastic bag, four plastic caps, four plastic pieces) were found in nine of 10,041 individuals. (Isoda et al., 2014). The sizes of these plastic items were smaller than $70 \times 70 \times 30 \mathrm{~mm}$ (excluding the plastic bag). The four cases of entanglement out of a total of 10,041 Antarctic minke whales that were examined involved fishing hooks, monofilament fishing lines, rope and packing bands. In both plastic ingested and entanglement, whales were not emaciated according to the usual body length-weight relationship.

In summary, the occurrence of floating macro debris documented in the JARPA/JARPAII (Isoda et al., 2014) and IDCR/SOWER programs were generally low. However, the numbers of sighting records of floating macro debris increased in the later years, particularly in Areas IV and V. Given the low numbers of records of marine debris, the effect on the Antarctic minke whale in the Antarctic Ocean is expected to be limited at the present time (Isoda et al., 2014; IWC, 2015c). The JARPAII Review panel commended the collection of these data that could provide a valuable baseline dataset, and recommended these data continue to be collected, and periodically analysed and presented to the IWC/SC (IWC, 2015c).

\section{CONCLUSIONS}

After many years of working on an in-depth assessment of Antarctic minke whales, the authors' believe that it is timely to summarise what has been achieved and identify those outstanding issues that are feasible and/or worthwhile to address in the future. This in-depth assessment began by trying to understand the abundance trends observed in sightings surveys conducted over the period 1984 to 2004, but expanded to cover population dynamics, biological characteristics and eclological/environmental interactions of the Antarctic minke whale. Our summary of the main conclusions from the IWC/SC in-depth assessment is provided below.

\section{Stock structure}

(1) There are two stocks (at least), namely an eastern Indian Ocean Stock (I-stock) and a western South Pacific Ocean Stock (P-stock), in Areas III East, IV, V and VI West $\left(35^{\circ} \mathrm{E}-145^{\circ} \mathrm{W}\right)$.
(2) The spatial distributions of the two stocks reflect a soft boundary in Area IV East $\left(100-130^{\circ} \mathrm{E}\right)$ and V West (130$\left.165^{\circ} \mathrm{E}\right)$, whose position changes by year and sex.

\section{Abundance}

(1) The numbers presented in Table 2 represent the best available abundance estimates in the surveyed areas during the IDCR/SOWER CPII and CPIII time periods.

(2) These estimates are subject to some degree of negative bias because the surveyed areas did not include waters to the north and south (i.e. within sea ice) where Antarctic minke whales are known to occur.

(3) A null hypothesis of no change in overall abundance between CPII and CPIII was not rejected because the ratio of total abundance in CPIII to CPII, formerly 0.47 with the standard method, was now estimated to be 0.69 with $95 \%$ CI $[0.43,1.13]$.

(4) Attempts have been made to estimate abundance in the sea ice field using aerial survey data, but at the time of this paper, absolute abundance estimates have not been obtained because of lack of correction for availability bias, which requires: (a) information on time-at-depth across a range of ice conditions; and (b) information on the visibility of Antarctic minke whales from the air as a function of depth and water clarity. If such estimates are developed in the future, correction of the survey estimates provided in Table 2 will be problematic because of a lack of sighting data in the sea ice field at times when the IDCR/SOWER and JARPA/JARPAII surveys were taking place.

\section{Biological information}

(1) Several biological parameters were estimated for I- and P-stocks based on JARPA/JARPAII samples, which are less biased samples than those from the commercial catch.

\section{Population dynamics}

(1) Relative trends estimated by the SCAA are generally robust to assumptions, with abundance peaking around 1970 following an increase from the 1930s. The early and peak abundances have higher CVs than recent abundance;

(2) Trends in abundance over the most recent 20 years (i.e. between CPII and CPIII) are relatively flat for the I-stock and decreasing for the P-stock. Differences can be explained as variability in distribution;

(3) MSYR is not estimated robustly; and

(4) $M$ (natural mortality) is higher for the lower and higher ages, and not statistically different between stocks.

\section{Investigations into plausible reasons for the decline in abundance}

(1) Predation by killer whales is unlikely to be a major reason for any change in Antarctic minke whale abundance between CPII and CPIII when the estimated consumption rate of killer whales is considered in conjunction with their estimated abundance; 
(2) Considerably more data and improved analytical techniques (e.g. with respect to spatial modelling and multi-species/ecosystem modelling) are needed before any firm conclusions on interspecific interactions between baleen whale populations in the Antarctic can be drawn;

(3) Considerable field and laboratory work was undertaken to produce preliminary daily food consumption rates of Antarctic minke whales sampled in the JARPA/JARPAII programs and krill biomass estimates derived from acoustic surveys. This is a positive step forward; however, additional data collection and analyses are needed to address the difficult task of providing the input data and developing an ecosystem model that would address the competition hypothesis;

(4) A decline in blubber thickness and in fat weight occurred during the JARPA period from $1987 / 88$ to $2004 / 05$ and was statistically significant at the $5 \%$ level;

(5) Levels of legacy pesticides in Area $\mathrm{V}$ decreased significantly with year during the JARPA/JARPAII period, while there was no trend in PCB levels;

(6) Very low tissue levels of organochlorides and mercury pollutants collected during JARPA/JARPAII point toward a lack of their effect on whale populations; and

(7) Given the low numbers of records of marine debris, the effect on the Antarctic minke whale in the Antarctic Ocean is expected to be limited at the present time. It was also recognised that these data could provide a valuable baseline dataset, and recommended these data continue to be collected, and periodically analysed and presented to the IWC/SC.

\section{ACKNOWLEDGEMENTS}

The authors acknowledge the scientists who were involved in the prolonged discussions on the IA which was led by one of the authors of this paper, Dr. Debra Palka, who was the chair of the IWC/SC IA sub-committee. Data used in the assessment were accumulated through large scale surveys which required substantial amounts of investment by the contracting governments and the IWC, who also provided the logistical support required for subsequent analyses. The authors express their thanks to the contracting governments and the IWC for creating the opportunities that have led to the results reported in this paper. The authors also express their thanks to the crews and researchers who participated in the surveys that were conducted in a harsh environment in order to collect data which were essential for this assessment. It would not have been possible to complete this assessment without the devotion, patience and scientific passion of all those involved. Comments from reviewers greatly improved the manuscript.

\section{REFERENCES}

Ainley, D.G., Dugger, K.M., Toniolo, V. and Gaffney, I. 2007. Cetacean occurrence patterns in the Amundsen and southern Bellingshausen sea sector, Southern Ocean. Mar. Mamm. Sci. 23: 287-305.

Allison, C. 2016. IWC individual catch database Version 6.1; Date: 18 July 2016 [Available from the Office of the International Whaling Commission].
Amante, C. and Eakins, B.W. 2009. ETOPO1 1 Arc-Minute Global Relief Model: Procedures, Data Sources and Analysis. NOAA Technical Memorandum NESDIS NGDC-24.

Armstrong, A.J., and Siegfried, W.R. 1991. Consumption of Antarctic krill by minke whales. Antarct. Sci. 3:13-18.

Arnason, U., Gullberg, A. and Widegren, B. 1993. Cetacean mitochondrial DNA control region: sequences of all extant baleen whales and two sperm whale species. Mol. Biol. Evol. 10: 960-70.

Arnold, P., Marsh, H. and Heinsohn, G. 1987. The occurrence of two forms of minke whales in east Australian waters with a description of external characters and skeleton of the diminutive or dwarf form. Sci. Rep. Whales Res. Inst., Tokyo 38:1-46.

Bando, T. and Hakamada, T. 2014. Yearly trend in the proportion of pregnant animals among mature female Antarctic minke whales in the JARPA and JARPAII period. Paper SC/F14/J09 presented to the Expert Workshop to Review the Japanese JARPAII Special Permit Research programme, February 2014 (unpublished). 6pp. [Available from the Office of this Journal].

Bando, T., Kishiro, T. and Kato, H. 2014. Yearly trend in the age at sexual maturity of Antarctic minke whales examined by transition phase in earplugs collected during JARPA and JARPA II surveys. Paper SC/F14/J08 presented to the Expert Workshop to Review the Japanese JARPAII Special Permit Research programme, February 2014 (unpublished). 10pp. [Available from the Office of this Journal].

Bando, T., Zenitani, R. and Fujise, Y. 2006a. A study on stock structure in the Antarctic minke whales from the JARPA research area based on analysis of body length of physically matured whales. Paper SC/D06/J11 presented to the Intersessional Workshop to Review Data and Results from Special Permit Research on Minke Whales in the Antarctic, December 2006 (unpublished). 7pp. [Available from the Office of this Journal].

Bando, T., Zenitani, R., Fujise, Y., Hakamada, T. and Kato, H. 2006 b. Biological parameters of the Antarctic minke whale based on materials collected by the JARPA survey in $1987 / 88$ to $2004 / 05$. Paper SC/D06/J17 presented to the Intersessional Workshop to Review Data and Results from Special Permit Research on Minke Whales in the Antarctic, Tokyo, December 2006 (unpublished). 28pp. [Available from the Office of this Journal].

Beekmans, B.W.P.M., Forcada, J.F., Murphy, E.J., de Baar, H.J.W., Bathmann, U.V. and Fleming, A.H. 2010. Generalised additive models to investigate environmental drivers of Antarctic minke whale (Balaenoptera bonaerensis) spatial density in austral summer. $J$. Cetacean Res. Manage. 11: 115-29.

Bergh, M.O., Butterworth, D.S. and Punt, A.E. 1991a. Further examination of the potential information content of age-structure data from Antarctic minke whale research catches. Rep. int. Whal. Commn 410:349-61.

Bergh, M.O., Butterworth, D.S., and Punt, A.E. 1991b. Initial evaluations of the information content of catch-age data using the 'Appendix 3' protocol. Paper SC/43/O16 presented to the IWC Scientific Committee, May 1991 (unpublished) 14pp. [Available from the Office of this Journal].

Best, P.B. 1985. External characters of southern minke whales and the existence of a diminutive form. Sci. Rep. Whales Res. Inst. Tokyo 36:1-33.

Borchers, D. and Burt, L. 2002. Generalised regression methods for estimating school size from line transect data. Paper SC/54/IA23 presented to the IWC Scientific Committee, April-May 2002 (unpublished). 10pp. [Available from the Office of this Journal].

Branch, T.A. 2005. Combining estimates from the third circumpolar set of surveys. J. Cetacean Res. Manage. (Suppl.) 7:231-33.

Branch, T.A. 2006. Abundance estimates for Antarctic minke whales from three completed circumpolar sets of surveys, 1978/79 to 2003/04. Paper SC/58/IA8 presented to the IWC Scientific Committee, May-June 2006 (unpublished). 40pp. [Available from the Office of this Journal]

Branch, T.A. 2007. Abundance of Antarctic blue whales south of $60^{\circ} \mathrm{S}$ from three complete circumpolar sets of surveys. J. Cetacean Res. Manage. 9: 253-62.

Branch, T.A. 2011. Humpback whale abundance south of $60^{\circ} \mathrm{S}$ from three completed sets of IDCR/SOWER circumpolar surveys. J. Cetacean Res. Manage. (special issue) 3: 53-69.

Branch, T.A. and Butterworth, D.S. 2001a. Southern Hemisphere minke whales: standardised abundance estimates from the $1978 / 79$ to $1997 / 98$ IDCR-SOWER surveys. J. Cetacean Res. Manage. 3: 143-74.

Branch, T.A. and Butterworth, D.S. 2001b. Estimates of abundance south of $60^{\circ} \mathrm{S}$ for cetacean species sighted frequently on the $1978 / 79$ to $1997 / 98$ IWC/IDCR-SOWER sighting surveys. J. Cetacean Res. Manage. 3: 25170.

Branch, T.A. and P. Ensor. 2004. Combining estimates from the third circumpolar set of surveys. J. Cetacean Res. Manage. (Suppl.) 6:239-40.

Branch, T.A. and Williams, T.M. 2006. Legacy of industrial whaling: Could killer whales be responsible for declines of sea lions, elephant seals, and 
minke whales in the Southern Hemisphere? pp.262-78. In: J.A. Estes, D.P. Demaster, D.F. Doak, T.M. Williams and R.L. Brownell, Jr. (eds) Whales, Whaling, and Ocean Ecosystems. University of California Press, Berkeley, California. 402pp.

Brandão, A. and Butterworth, D.S. 2002. Further results concerning the closing:IO mode density ratio, R, for the IDCR-SOWER surveys. Paper SC/54/IA26 presented to the IWC Scientific Committee, April-May 2002 (unpublished). 13pp. [Available from the Office of this Journal].

Brandão, A., Rademeyer, R.A. and Butterworth, D.S. 2001. Estimation of mean school size for minke whales from IWC/IDCR-SOWER surveys.Paper SC/53/IA26 presented to the IWC Scientific Committee, July 2001 (unpublished). 21pp. [Available from the Office of this Journal].

Bravington, M.V. 2002. Spatial analyses of Southern Hemisphere minke whale data, allowing for size bias and sightability. Paper SC/54/IA21 presented to the IWC Scientific Committee, April-May 2002 (unpublished). 18pp. [Available from the Office of this Journal].

Buckland, S.T. and Duff, E.I. 1989. Analysis of the Southern Hemisphere minke whale mark-recovery data. Rep. int. Whal. Commn (special issue) 11:121-43.

Buckland, S.T. and Turnock, B.J. 1992. A robust line transect method. Biometrics 48: 901-9.

Burt, M.L. 2004. Overview of the standard dataset of IDCR/SOWER data. Paper SC/56/IA2 presented to the IWC Scientific Committee, June-July 2004 (unpublished). 3pp. [Available from the Office of this Journal].

Burt, M.L. and Hughes, M.S. 2002. A note on using different analysis options on abundance estimates using IWC-SOWER 1998/99 survey as an example. Paper SC/54/IA5 presented to the IWC Scientific Committee, April-May 2002 (unpublished). 12pp. [Available from the Office of this Journal].

Burt, M.L. and Paxton, C.G.M. 2006. Review of density surface modeling applied to JARPA survey data. Paper SC/D06/J4 presented to the Intersessional Workshop to review data and results from special permit research on minke whales in the Antarctic, December 2006. (unpublished). 5pp. [Available from the Office of this Journal].

Bushuev, S.G. 1986. Feeding of minke whales, Balaenoptera acutorostrata, in the Antarctic. Rep. int. Whal. Commn 36:241-5.

Butterworth, D.S. and Punt. A.E. 1990. Some preliminary examinations of the potential information content of age-structure data from Antarctic minke whale research catches. Rep. int. Whal. Commn 40:301-15.

Butterworth, D.S., Punt, A.E., Geromont, H.F., Kato, H. and Miyashita T. 1996. An ADAPT approach to the analysis of catch-at-age information for Southern Hemisphere minke whales. Rep. int. Whal. Commn 46:34959.

Butterworth, D.S., Punt, A.E., Geromont, H.F., Kato, H. and Fujise, Y. 1999. Inferences on the dynamics of Southern Hemisphere minke whales from ADAPT analyses of catch-at-age information. J. Cetacean Res. Manage. $1: 11-32$.

Butterworth, D.S., Punt, A.E., Branch, T.A., Fujise, Y., Zenitani, R. and Kato, H. 2002. Updated ADAPT VPA recruitment and abundance trend estimates for Southern Hemisphere minke whales in Areas IV and V. Paper SC/54/IA25 presented to the IWC Scientific Committee, AprilMay 2002 (unpublished) 18pp. [Available from the Office of this Journal].

Butterworth, D.S., Rademeyer, R.A. and Brandão, A. 2001. First attempts to quantify some factors that potentially confound temporal comparisons of minke whale abundance estimates from the IWC/IDCR-SOWER surveys. Paper SC/53/IA27 presented to the IWC Scientific Committee, July 2001 (unpublished). 21pp. [Available from the Office of this Journal].

Christiansen, F., Víkingsson, G., Rasmussen, M.H. and Lusseau, D. 2013. Minke whales maximise energy storage on their feeding grounds. J. Exp. Biol. 216:427-36.

Committee on Taxonomy. 2016. List of marine mammal species and subspecies. Society for Marine Mammalogy. At: https://www.marine mammalscience.org, Consulted on 11 March 2017.

Cooke, J.G. 2002. Progress report on analysis of IDCR/SOWER data. Paper SC/54/IA1 presented to the IWC Scientific Committee, April-May 2002 (unpublished). 7pp. [Available from the Office of this Journal].

de la Mare, W.K. 1989. Report of the Scientific Committee, Annex L. The model used in the Hitter and Fitter programs (Program: FITTER. SC40). Rep. Int. Whal. Commn 39:150-1.

de la Mare, W.K. 2011. Are reported trends in Antarctic minke whale body condition reliable? Paper SC/63/O16 presented to the IWC Scientific Committee, June 2011 (unpublished). 25pp. [Available from the Office of this Journal].

de la Mare, W.K. 2012. Lurking variables and the interpretation of statistical analyses of data collected under JARPA. Paper SC/63/O16 presented to the IWC Scientific Committee, June 2012 (unpublished). 65pp. [Available from the Office of this Journal]. de la Mare, W.K. 2013. Implications of energy budgets in determining the characteristics of whale yield curves (Draft). Paper SC/M13/MSYR2 presented to the Fourth Intersessional Workshop on the Review of Maximum Sustainable Yield Rates (MSYR) in Baleen Whales, March 2013 (unpublished). 129pp. [Available from the Office of this Journal].

de la Mare, W., Candy, S., McKinlay, J., Wotherspoon, S. and Double, M. 2014. What can be concluded from the statistical analyses of JARPA JARPA II body condition data? Paper SC/F14/O06 presented to the JARPA II Special Permit Expert Panel Review Workshop, February 2014 (unpublished). 58pp. [Available from the Office of this Journal].

Donovan, G.P. 1991. A review of IWC stock boundaries. Rep. int. Whal. Commn (special issue) 13:39-68.

Ensor, P. H. 1989. Minke whales in the pack ice zone, east Antarctica, during the period of maximum annual ice extent. Rep. int. Whal. Commn 39:219-25.

Ensor, P., Cawthorn, M., Corkeron, P., Matsuoka, K., Narita, H., Pitman, R., Sekiguchi, K. and Sumihara, T. 1996. 1995-96 IWC/IDCR Southern Hemisphere Minke Whale Assessment Cruise, Area VI. Paper SC/48/SH2 presented to the IWC Scientific Committee, June 1996 (unpublished). $45 \mathrm{pp}$. [Available from the Office of this Journal].

Ensor, P., Findlay, K., Friedrichsen, G., Hirose, K., Komiya, H., Morse, L. Olson, P., Sekiguchi, K., Van Waerebeek, K. and Yoshimura, I. 2005. 2004-2005 International Whaling Commission-Southern Ocean Whale and Ecosystem Research (IWC-SOWER) cruise, Area III Paper SC/57/IA1, presented to the IWC Scientific Committee, May 2005 (unpublished). 85pp. [Available from the Office of this Journal].

Ensor, P., Komiya, H., Kumagai, S., Kuningas, S., Olson, P. and Tsuda, Y. 2009. 2008-2009 International Whaling Commission-Southern Ocean Whale and Ecosystem Research (IWC-SOWER) Cruise. Paper SC/61/IA19 presented to the IWC Scientific Committee, May 2009 (unpublished). 55pp. [Available from the Office of this Journal].

Ensor, P., Matsuoka, K., Hirose, K., Ljungblad, D., Minami, K., Olson, P., Rankin, S., Stevick, P., Tsunekawa, M. and Ugarte, F. 2003. 2002-2003 International Whaling Commission-Southern Ocean Whale and Ecosystem Research (IWC-SOWER) Circumpolar Cruise, Areas V. 2003. Paper SC/55/IA1 presented to the IWC Scientific Committee, May-June 2003 (unpublished). 65pp. [Available from the Office of this Journal].

Ensor, P., Matsuoka, K., Komiya, H., Ljungblad, D., Miura, T., Morse, L., Olson, P., Olavarría, C., Mori, M. and Sekiguchi, K. 2004. 2003-2004 International Whaling Commission-Southern Ocean Whale and Ecosystem Research (IWC-SOWER) Circumpolar Cruise, Areas V. 2004 Paper SC/56/IA13 presented to the IWC Scientific Committee, June-July 2004 (unpublished). 54pp. [Available from the Office of this Journal].

Ensor, P., Minami, K., Morse, L., Olson P. and Sekiguchi, K. 2008. $2007-$ 2008 International Whaling Commission-Southern Ocean Whale and Ecosystem Research (IWC-SOWER) cruise. Paper SC/60/IA1 presented to the IWC Scientific Committee, May-June 2008 (unpublished). 51pp. [Available from the Office of this Journal].

Ensor, P., Rowlett, R., Hansen, J., Kira, M., Mermoz, J., Newcomer, M., Nishiwaki, S., Onodera, E. and Shimada, H. 1992. 1991-92 IWC/IDCR Southern Hemisphere Minke Whale Assessment Cruise, Area V. Paper SC/44/SHB4 presented to the IWC Scientific Committee, June-July 1992 (unpublished). 32pp. [Available from the Office of this Journal].

Ensor, P., Sekiguchi, K., Cotton, J., Hucke-Gaete, R., Kariya, T., Komiya, H., Ljungblad, D., Narita, H., Olson, P. and Rankin, S. 2002. 20012002 International Whaling Commission-Southern Ocean Whale and Ecosystem Research (IWC-SOWER) Circumpolar Cruise, Areas V. 2002. Paper SC/54/IA2 presented to the IWC Scientific Committee, AprilMay 2002 (unpublished). 50pp. [Available from the Office of this Journal].

Ensor, P., Sekiguchi, K., Doherty, J., Kleivane, L., Ljungblad, D., Marques, F., Matsuoka, K., Narita, H., Pitman, R. and Sakai, K. 1999. 1998-99 IWC-Southern Ocean Whale and Ecosystem Research (IWC-SOWER) Antarctic Cruise, Areas III and IV. Paper SC/51/CAWS6 presented to the IWC Scientific Committee, May 1999 (unpublished). 61pp. [Available from the Office of this Journal].

Ensor, P., Shimada, H., Brown, M., Cawthorn, M., Findlay, K., Gomi, K., Hara, T. and Kawasaki, M. 1995. 1994-95 IWC/IDCR Southern Hemisphere Minke Whale Assessment Cruise. Paper SC/47/SH2 presented to the IWC Scientific Committee, May-June 1995 (unpublished). 45pp. [Available from the Office of this Journal].

Fournier, D. and Archibald, C.P. 1982. A general theory for analyzing catch at age data. Can. J. Fish. Aquat. Sci. 39:1,195-207.

Friedlaender, A.S., Goldbogen, J.A., Nowacek, D.P., Read, A.J., Johnston, D. and Gales, N. 2014. Feeding rates and under-ice foraging strategies of the smallest lunge filter feeder, the Antarctic minke whale (Balaenoptera bonaerensis). J. Exp. Biol. 217: 2851-4.

Friedlaender, A.S., Johnston, D.W., Goldbogen, J.A., Tyson, R.B., Stimpert, A.K., Hazen, E.L., Kaltenberg, A. and Nowacek, D.P. 2016. Two-step decisions in a marine central-place forager. R. Soc. Open Sci. 3: 160043. 
Fujise, Y. 1995. A preliminary morphometric study in minke whales from Antarctic Area IV using data from the 1989/90 JARPA Survey. Paper SC/47/SH7 presented to the IWC Scientific Committee, May 1995 (unpublished). 15pp [Available from the Office of this Journal].

Gavaris, S. 1988. An adaptive framework for the estimation of population size. Res. Doc. Can. Atl. Fish. scient. Adv. Commn. (CAFSAC) 88/29. $12 \mathrm{pp}$ (mimeo).

George, J.C., Bada, J., Zeh, J., Scott, L., Brown, S.E., O’Hara, T. and Suydam, R. 1999. Age and growth estimates of bowhead whales (Balaena mysticetus) via aspartic acid racemization. Can. J. Zool. 77: 571-80.

Glover, K.A., Kanda, N., Haug, T., Pastene, L.A., Øien, N., Goto, M., Seliussen, B.B. and Skaug, H.J. 2010. Migration of Antarctic minke whales to the Arctic. PlosOne 5:e15197.

Glover, K.A., Kanda, N., Haug, T., Pastene, L.A., Øien, N., Seliusen, B.B., Sørvik, A.G.E. and Skaug, H.J. 2013. Hybrids between common and Antarctic minke whales are fertile and can back-cross. BMC Genetics $14: 25$.

Government of Japan 1987. The program for research on the Southern Hemisphere minke whale and for preliminary research on the marine ecosystem in the Antarctic. Paper SC/39/O4 presented to the IWC Scientific Committee, June 1987 (unpublished). 60pp. [Available from the Office of this Journal]

Government of Japan 1989. The research plan in 1989/90 season in conjunction with note for 'The program for research on the Southern Hemisphere minke whale and for preliminary research on the marine ecosystem in the Antarctic (SC/39/O4)'. Paper SC/41/SHMi13 presented to the IWC Scientific Committee, 1989 (unpublished). 21pp. [Available from the Office of this Journal].

Government of Japan 1995. The 1995/96 research plan for the Japanese Whale Research Program under Special Permit in the Antarctic. Paper SC/47/SH3 presented to the IWC Scientific Committee, May 1995 (unpublished). 8pp. [Available from the Office of this Journal].

Government of Japan. 1996. The 1996/97 research plan for the Japanese whale research program under special permit in the Antarctic [plus Addendum]. Paper SC/48/SH3 presented to the IWC Scientific Committee, June 1996 (unpublished). 14pp. [Available from the Office of this Journal].

Government of Japan. 2005. Plan for the second phase of the Japanese whale research program under special permit in the Antarctic (JARPA II) Monitoring of the Antarctic ecosystem and development of new management objectives for whale resources. Paper SC/57/O1 presented to the IWC Scientific Committee, May-June 2005 (unpublished). 99pp. [Available from the Office of this Journal].

Hakamada, T. 2006. Morphometric analysis on stock structure in the Antarctic minke whale based on JARPA samples. Paper SC/D06/J10 presented to the Intersessional Workshop to Review Data and Results from Special Permit Research on Minke Whales in the Antarctic, Tokyo December 2006. (unpublished) 8pp. [Available from the Office of this Journal]

Hakamada, T and Matsuoka, K. 2002. An examination of the effect of alternative pooling strata in the estimation of abundance in the Antarctic minke whale. Paper SC/54/IA13 presented to the IWC Scientific Committee, April-May 2002 (unpublished). 27pp. [Available from the Office of this Journal].

Hakamada, T. and Matsuoka, K. 2014a. Estimates of abundance and abundance trend of the Antarctic minke whale in Areas IIIE-VIW, south of $60^{\circ} \mathrm{S}$, based on JARPA and JARPAII sighting data (1989/90-2008/09). Paper SC/F14/J03 presented to the Expert Workshop to Review the Japanese JARPA II Special Permit Research Programme, February 2014. (unpublished). 41pp. [Available from the Office of this Journal]

Hakamada, T. and Matsuoka, K. 2014b. Estimates of abundance and abundance trend of the humpback whale in Areas IIIE-VIW, south of $60^{\circ} \mathrm{S}$, based on JARPA and JARPA II sighting data (1989/90-2008/09). Paper SC/F14/J04 presented to the Expert Workshop to Review the Japanese JARPA II Special Permit Research Programme, February 2014 (unpublished). 36pp. [Available from the Office of this Journal].

Hakamada, T., Matsuoka, K. and Nishiwaki, S. 2006. An update of Antarctic minke whales abundance estimate based on JARPA data. Paper SC/D06/J6 presented to the Intersessional Workshop to Review Data and Results from Special Permit Research on Minke Whales in the Antarctic, December 2006. (unpublished). 34pp. [Available from the Office of this Journal].

Hakamada, T., Matsuoka, K., Nishiwaki, S. and Kitakado, T. 2013. Abundance estimates and trends for Antarctic minke whales (Balaenoptera bonaerensis) in Antarctic Areas IV and V for the period 1989/90-2004/05. J. Cetacean Res. Manage. 13: 123-51.

Haug, T., Lindstrøm, U. and Nilssen, K.T. 2002. Variations in minke whale (Balaenoptera acutorostrata) diet and body condition in response to ecosystem changes in the Barents Sea. Sarsia 87: 409-22

Haw, M.D. 1991. An investigation into the differences in minke whale school density estimates from passing mode and closing mode survey in IDCR Antarctic assessment cruises. Rep. int. Whal. Commn 41: 313-30.
Hedley, S.L., Buckland, S.T. and Borchers, D.L. 1999. Spatial modelling from line transect data. J. Cetacean Res. Manage. 1: 255-64.

Herr, H., Kelly, N., Viquerat, S., Kock, K-H., Williams, R., Scheidat, M., Lehnert, L.S. and Siebert, U. 2014. Overview of five German helicopter surveys provide insight into spatio-temporal variability of minke whale densities in ice. Paper SC/65b/IA16 presented to the IWC Scientific Committee, May 2014 (unpublished). 15pp. [Available from the Office of this Journal].

Hoelzel, A.R. and Dover, G.A. 1989. Molecular techniques for examining genetic variation and stock identity in cetacean species. Rep. int. Whal. Commn (special issue) 11:81-120.

Horwood, J. 1990. Biology and Exploitation of the Minke Whale. CRC Press, Inc., Boca Raton Florida. 238p.

Ichii, T. 1990. Distribution of Antarctic krill concentrations exploited by Japanese krill trawlers and minke whales. Proc. NIPR Symp. Polar Biol. 3:34-45.

Ichii, T. and Kato, H. 1991. Food and daily food consumption of southern minke whales in the Antarctic. Polar Biol. 11:479-87.

Ichii, T., Shinohara, N., Fujise, Y., Nishiwaki, S. and Matsuoka, K. 1998. Interannual changes in body fat condition index of minke whales in the Antarctic. Mar. Ecol. Prog. Ser. 175: 1-12.

International Whaling Commission. 1980. Report of the Scientific Committee. Rep. int. Whal. Commn 30: 42-59.

International Whaling Commission. 1984. Report of the Minke Whale Ageing Workshop. Rep. int. Whal. Commn 34: 42-59.

International Whaling Commission. 1987. Report of the Special Meeting of the Scientific Committee on Planning for a Comprehensive Assessment of Whale Stocks. Rep. int. Whal. Commn 37: 147-57.

International Whaling Commission. 1991a. Report of the Scientific Committee. Rep. int. Whal. Commn 41: 675-88.

International Whaling Commission. 1991b. Report of the Scientific Committee, Annex E. Report of the Sub-Committee on Southern Hemisphere Minke Whales. Rep. int. Whal. Commn 41: 113-31.

International Whaling Commission. 1994. Chairman's Report of the FortyFifth Annual Meeting, Appendix 12. Resolution on research on the environment and whale stocks. Rep. int. Whal. Commn 44: 35.

International Whaling Commission. 1995a. Chairman's Report of the FortySixth Annual Meeting. Rep. int. Whal. Commn 45: 15-52.

International Whaling Commission. 1995b. POLLUTION 2000+: after Barcelona, Annex C. Report of the Scientific Committee. Rep. int. Whal. Commn 45:53-103.

International Whaling Commission 1998. Report of the Intersessional Working Group to Review Data and Results from Special Permit Research on Minke Whales in the Antarctic, Tokyo, 12-16 May 1997. Rep. int. Whal. Commn 48: 377-412.

International Whaling Commission 1999. Report of the Scientific Committee, Annex G. Report of the Sub-Committee on Other Great Whales. J. Cetacean Res Manage (Suppl.) 1: 117-55.

International Whaling Commission. 2000. Report of the Sub-Committee on the Comprehensive Assessment of Whale Stocks - In Depth Assessments. J. Cetacean Res Manage (Suppl.) 2: 177-208.

International Whaling Commission. 2001a Report of the Scientific Committee. J. Cetacean Res Manage (Suppl.) 3: 1-76.

International Whaling Commission. 2001b Report of the Working Group on Nomenclature. J. Cetacean Res Manage (Suppl.) 3:363.

International Whaling Commission. 2002. Summary of historical changes to the 'standard methodology'. J. Cetacean Res Manage (Suppl 4:218.

International Whaling Commission 2003a. Report of the Scientific Committee, Annex G. Report of the Sub-Committee on the Comprehensive Assessment of Whale Stocks - In Depth Assessments. J. Cetacean. Res. Manage. (Suppl.) 5:248-92.

International Whaling Commission 2003b. Report of the Scientific Committee, Annex G, Appendix 10. Hypotheses that may explain why the estimates of abundance for the third circumpolar set of survey (CP) using the 'standard methods' are appreciably lower than estimates for the second CP. J. Cetacean. Res. Manage. (Suppl.) 5:286-90.

International Whaling Commission 2004. Report of the Scientific Committee, Annex G. Report of the Sub-Committee on the Comprehensive Assessment of Whale Stocks - In Depth Assessments. J. Cetacean. Res. Manage. (Suppl.) 6:248-92.

International Whaling Commission 2005. Report of the Scientific Committee, Annex G. Report of the Sub-Committee on the Comprehensive Assessment of Whale Stocks - In Depth Assessments. J. Cetacean. Res. Manage. (Suppl.) 7:224-45.

International Whaling Commission. 2006. Report of the Joint Symposium on High Latitude Sea Ice Environments: Effects on Cetacean Abundance, Distribution and Ecology. J. Cetacean. Res. Manage. (Suppl.) 8:367-83.

International Whaling Commission. 2007. Report of the Scientific Committee. J. Cetacean. Res. Manage. (Suppl.) 9: 1-73.

International Whaling Commission. 2008a. Report of the Scientific Committee. J. Cetacean Res. Manage. 10 (Suppl.): 1-74. 
International Whaling Commission. 2008b. Report of the Intersessional Workshop to Review Data and Results from Special Permit Research on Minke Whales in the Antarctic, Tokyo, 4-8 December 2006. J. Cetacean. Res. Manage. (Suppl.) 10:411-45.

International Whaling Commission. 2009. Report of the SOWER Abundance Workshop. J. Cetacean. Res. Manage. (Suppl. 1) 11:455-63. International Whaling Commission. 2010. Report of the SOWER Abundance Workshop. J. Cetacean Res. Manage. (Suppl. 2) 11:509-19.

International Whaling Commission. 2011. Report of the Scientific Committee. Annex G. Report of the Sub-Committee on In-Depth Assessments. J. Cetacean Res. Manage. (Suppl.) 12:185-202.

International Whaling Commission. 2012. Report of the Intersessional IA Workshop on Estimating Abundance of Antarctic Minke Whales. J. Cetacean Res. Manage. (Suppl.) 13:363-68.

International Whaling Commission. 2013a. Report of the Scientific Committee. J. Cetacean Res. Manage. (Suppl.) 13:1-86

International Whaling Commission. 2013b. Report of the 2012 Intersessional IA Workshop on Estimating Abundance of Antarctic Minke Whales. J. Cetacean Res. Manage. (Suppl.) 13:387-91.

International Whaling Commission. 2014. Report of the IWC Scientific Committee Workshop on Marine Debris. J. Cetacean Res. Manage. (Suppl.) 15: 519-41.

International Whaling Commission. 2015a. Report of the Scientific Committee. J. Cetacean Res. Manage. (Suppl.) 16:1-87.

International Whaling Commission. 2015b. Report of the Scientific Committee. Annex G. Report of the Sub-Committee on In-Depth Assessment. J. Cetacean Res. Manage. (Suppl.) 16:176-95.

International Whaling Commission. 2015c. Report of the Expert Workshop to Review the Japanese JARPAII Special Permit Research Programme. J. Cetacean Res. Manage. (Suppl.) 16:369-409.

International Whaling Commission. 2019. Report of the Scientific Committee. J. Cetacean Res. Manage. (Suppl.) 20:1-78.

Isoda, T., Tamura, T., Nishiwaki, S and Pastene, L.A. 2014. Observation of marine debris in the Antarctic based on JARPA and JARPAII data. Paper SC/F14/J22 presented to the Expert Workshop to Review the Japanese JARPA II Special Permit Research Programme, February 2014 (unpublished). 11pp. [Available from the Office of this Journal].

Jonsgard, A.1951. Studies on the little piked whale or minke whale (Balaenoptera acuto-rostrata Lacèpéde). Norsk Hvalfangst-Tidende $5: 209-32$.

Joyce, G., Ensor, P., Danielsen, F., Desportes, G., Mermoz, J., Nakanishi., S., Nishiwaki, S., Ohizumi, H. and Turui, T. 1991. Report of the 199091 IWC/IDCR Southern Hemisphere Minke Whale Assessment Cruise, Area VI. Paper SC/43/Mi33 presented to the IWC Scientific Committee, May 1991 (unpublished). 32pp. [Available from the Office of this Journal].

Joyce, G., Kasamatsu, F., Ensor, P., Nakanishi, S., Rowlett, R., Shigemune, H., Troutman, B. and Yamashita, K. 1988. Report of the 1987-88 IWC/IDCR Southern Hemisphere Minke Whale Assessment Cruise, Area III. Paper SC/40/Mi2 presented to the IWC Scientific Committee, MayJune 1988 (unpublished). 23pp. [Available from the Office of this Journal].

Kanda, N., Goto, M. and Pastene, L.A. 2014. Update of stock structure of humpback whales in the Antarctic feeding grounds as revealed by microsatellite DNA data (SC/F14/J31 rev). Paper SC/65b/SD2 presented to the IWC Scientific Committee, May 2014 (unpublished). 6pp. [Available from the Office of this Journal].

Kasamatsu, F., Ensor, P., Mermoz, J., Shigemune, H., Nakanishi, S., Zorin, A., Da Silva, V., Newcomer, M. and Ohwada, A. 1989. Report of the 1988/89 IWC/IDCR Southern Hemisphere Minke Whale Assessment Cruise, Area IV. Paper SC/41/SHMi7 presented to the IWC Scientific Committee, June 1989 (unpublished). 19pp. [Available from the Office of this Journal].

Kasamatsu, F., Matsuoka, K. and Hakamada, T. 2000. Interspecific relationships in density among the whale community in the Antarctic. Polar Biol. 23:466-73.

Kasamatsu, F., Nishiwaki, S. and Ishikawa, H. 1995. Breeding areas and southbound migrations of southern minke whales, Balaenoptera acutorostrata. Mar. Ecol. Prog. Ser. 119:1-10.

Kasuya, T. and Ichihara, T. 1965. Some information on minke whales from the Antarctic. Sci. Rep. Whales Res. Inst. Tokyo 19:37-43.

Kato, H. 1992. Body length, reproduction and stock separation of minke whales off Northern Japan. Rep. int. Whal. Commn 42:443-53.

Kato, H. 1987. Density dependent changes in growth parameters of the southern minke whale. Sci. Rep. Whales Res. Inst. Tokyo 38: 47-73.

Kato, H. and Fujise, Y. 2000. Dwarf minke whales; Morphology, growth and life history with some analyses on morphometric variation among the different forms and regions. Paper SC/52/OS3 presented to the Scientific Committee, June 2000 (unpublished). 30pp. [Available from the Office of this Journal].
Kato, H., Fujise, Y., Nakamura, G., Pastene, L.A., Hakamada, T. and Best, P.B. 2015. Marked morphological and morphometric differentiation between Dwarf minke and Antarctic and Common minke whales. Bay 03 A7. Presented to the $21^{\text {st }}$ Biennial Conference on the Biology of Marine Mammals, Society of Marine Mammalogy, San Francisco, 13-18 December 2015. [Abstract].

Kato, H. and Sakuramoto, K. 1991. Age at sexual maturity of southern minke whales: a review and some additional analysis. Rep. int. Whal. Commn 41: 331-337.

Kawamura, A. 1980. A review of food of Balaenopterid whales. Sci. Rep. Whales Res. Inst., Tokyo 32:155-97.

Kelly, N., Murase, H., Kitakado, T., Kock, K-H., Williams, R., Feindtherr, H. and Walløe, L. 2012. Appraisal of methods and data to estimate abundance of Antarctic minke whales within sea ice covered areas of the Southern Ocean. Paper SC/64/IA10 presented to the IWC Scientific Committee, June 2012 (unpublished). 16pp. [Available from the Office of this Journal].

Kelly, N., Peel, D. Bravington, M. V. 2014. Distribution and abundance of Antarctic minke whales in sea ice regions of East Antarctica: a summary of results. Paper SC/65b/IA15 presented to the IWC Scientific Committee, May 2014 (unpublished). 7pp. [Available from the Office of this Journal]

Kelly, N., Peel, D., Pike, D., Bravington, M. and Gales, N. 2008. Aerial survey of minke whales off East Antarctica: report on 2007/08 test survey and future plan. Paper SC/60/IA4 presented to the IWC Scientific Committee, May 2008 (unpublished). 8pp. [Available from the Office of this Journal]

Kelly, N., Peel, D., Pike, D., Bravington, M. and Gales, N. 2009. An aerial survey for Antarctic minke whales in sea ice off east Antarctica: a pilot study. Paper SC/61/IA3 presented to the IWC Scientific Committee, May-June 2009 (unpublished). 14pp. [Available from the Office of this Journal].

Kelly, N., Peel, D., Bravington, M. V. and Gales. N. 2010. Aerial survey of minke whales off East Antarctica: Report on 2009/10 Survey. Paper SC/62/IA8 presented to the IWC Scientific Committee, May-June 2010 (unpublished). $24 \mathrm{pp}$. [Available from the Office of this Journal].

Kishino, H., Kato, H., Kasamatsu, F. and Fujise, Y. 1991. Detection of heterogeneity and estimation of population characteristics from the field survey data: 1987/88 Japanese feasibility study of the Southern Hemisphere minke whales. Ann. Inst. Stat. Math. 43: 435-53.

Kitakado, T., Murase, H., Tamura, T. and Yonezaki, S. 2014a. An attempt to ecosystem modelling for species in Area IV in the Antarctic Ocean using JARPA and JARPAII data. Paper SC/F14/J26 presented to the Expert Workshop to Review the Japanese JARPA II Special Permit Research Programme, February 2014 (unpublished) 15pp. [Available from the Office of this Journal].

Kitakado, T., Lockyer, C. and Punt, A.E. 2013. A statistical model for quantifying age-reading errors and its application to the Antarctic minke whales. J. Cetacean Res. Manage. 13: 181-90.

Kitakado, T., Schweder, T., Kanda, N., Pastene, L.A. and Walløe, L. 2014b. Dynamic population segregation by genetics and morphometrics in Antarctic minke whales (SC/F14/J29rev). Paper SC/65b/IA13 presented to the IWC Scientific Committee, May 2014 (unpublished). 25pp. [Available from the Office of this Journal].

Konishi, K., Tamura, T., Zenitani, R., Bando, T., Kato, H. and Walløe, L. 2008. Decline in energy storage in the Antarctic minke whale (Balaenoptera bonaerensis) in the Southern Ocean. Polar Biol. 31:1509-20.

Konishi, K. and Walloe, L. 2015. Substantial decline in energy storage and stomach fullness in Antarctic minke whales (Balaenoptera bonaerensis) during the 1990's. J. Cetacean Res. Manage. 15:77-92.

Laws, R.M. 1977. Seals and whales of the Southern Ocean. Phil. Trans. R. Soc. Lond., B 279: 81-96.

Leaper, R. and Lavigne, D. 2007. How much do large whale eat? J. Cetacean Res. Manage. 9:179-88

Lockyer, C. 1981. Estimation of the energy costs of growth, maintenance and reproduction in the female minke whale (Balaenoptera acutorostrata) from the southern hemisphere. Rep. int. Whal. Commn 31:337-43.

Lockyer, C. 1984. Age determination by means of earplugs in baleen whales. Rep. int. Whal. Commn 34: 692-6.

Lockyer. C. 1986. Body fat condition in Northeast Atlantic fin whales, Balaenoptera physalus, and its relationship with reproduction and food resource. Can. J. Fish. Aquat. Sci. 43:142-7.

Lockyer, C. 1987. The relationship between body fat, food resource and reproductive energy costs in north Atlantic fin whales (Balaenoptera physalus). Symp. Zool. Soc. Lond. 57:343-61

Lockyer C., McConnell, L. C., and Waters, T. D. 1985. Body condition in terms of anatomical and biochemical assessment of body fat in North Atlantic fin and sei whales. Can. J. Zool. 63:2328-38.

Mackintosh, N.A. 1942. The southern stocks of whalebone whales. Discovery Rep. 22:197-300. 
Mackintosh, N.A. 1966. The distribution of southern blue and fin whales. pp.125-44. In: K.S. Norris (ed.) Whales, Dolphins and Porpoises. University of California Press, Berkeley and Los Angeles. xv+789pp.

Matsuoka, K., Ensor, P., Hakamada, T., Shimada, H., Nishiwaki, S., Kasamatsu, F. and Kato, H. 2003a. Overview of minke whale sightings surveys conducted on IWC/IDCR and SOWER Antarctic cruises from 1978/79 to 2000/01. J. Cetacean Res. Manage. 5:173-201.

Matsuoka, K. and Hakamada, T. 2002 Applying alternative approach to Antarctic minke whale abundance estimation with an example for the part of Area IV using IWC/SOWER 1998/99 data. Paper SC/54/IA15 presented to the IWC Scientific Committee, April-May 2002 (unpublished). 18pp. [Available from the Office of this Journal].

Matsuoka, K. and Hakamada, T. 2014. Estimates of abundance and abundance trend of the blue, fin and southern right whales in Areas IIIEVIW, south of $60^{\circ} \mathrm{S}$, based on JARPA and JARPA II sighting data (1989/90-2008/09). Paper SC/F14/J05 presented to the Expert Workshop to Review the Japanese JARPA II Special Permit Research Programme, February 2014 (unpublished). 27pp. [Available from the Office of this Journal]

Matsuoka, K., Hakamada, T., Kimura, K. and Okada, Y. 2009. Influence of sea ice concentration on Antarctic minke whale abundance estimation in the Ross Sea. Paper SC/61/IA16 presented to the IWC Scientific Committee, May-June 2009 (unpublished). 7pp. [Available from the Office of this Journal].

Matsuoka, K., Hakamada, T., Kiwada, H., Murase, H. and Nishiwaki, S. 2005. Distribution and abundance of humpback, fin and blue whales in the Antarctic Areas IIIE, IV, V and VIW. Global Environ. Res. 9 :10515.

Matsuoka, K., Kiwada, H. and Hakamada, T. 2006. The relationships between sea ice extension and trends in sighting parameters of Antarctic minke whales based on IDCR-SOWER data from CPII to CPIII. Paper SC/58/IA17, presented to the IWC Scientific Committee, May-June 2006 (unpublished). 7pp. [Available from the Office of this Journal].

Matsuoka, K., Nishiwaki, S., Murase, H., Kanda, N., Kumagai, S. and Hatanaka, H. 2008. Influence of sea ice concentration in the research area on IDCR-SOWER abundance estimation. Paper SC/60/IA12 presented to the IWC Scientific Committee, June 2008 (unpublished). 9pp. [Available from the Office of this Journal].

Matsuoka, K., Watanabe, T., Ichii, T., Shimada, H. and Nishiwaki, S. 2003 b. Large whale distributions (south of $60^{\circ} \mathrm{S}, 35^{\circ} \mathrm{E}-130^{\circ} \mathrm{E}$ ) in relation to the southern boundary of the Antarctic Circumpolar Current. pp. 26-30. In: A.H.L. Huiskes, W.W.C. Gieskes, J. Rozema, R.M.L. Schorno, S.M. van der Vies and W.J. Wolff (eds). Antarctic Biology in a Global Context. Backhuys Publishers, Leiden. 338pp.

Miyashita, T., Shigemune, H. and Kato, H. 1993. Outline of sighting strategy of the scouting vessels attached to the Japanese fleets. Paper SC/45/SHBa9 presented to the IWC Scientific Committee, April-May 1993 (unpublished). [Available from the Office of this Journal].

Mori, M. and Butterworth, D.S. 2004. Consideration of multispecies interactions in the Antarctic: a preliminary model of the minke whale blue whale - krill interaction. Afr. J. Mar. Sci. 26: 245-59.

Mori, M. and Butterworth, D.S. 2006. A first step towards modelling the krill-predator dynamics of the Antarctic ecosystem. CCAMLR Sci. 13: 217-77.

Mori, M., Butterworth, D.S., Brandao, A., Rademeyer-Rebecca, A., Okamura, H. and Matsuda, H. 2003. Observer experience and Antarctic minke whale sighting ability in IWC/IDCR-SOWER surveys. $J$. Cetacean Res. Manage. 5: 1-11.

Mori, M., Butterworth, D.S. and Kitkado, T. 2007. Further progress on application of ADAPT-VPA to Antarctic minke. Paper SC/59/IA13 presented to the IWC Scientific Committee, May 2007 (unpublished) 32pp. [Available from the Office of this Journal].

Mori, M., Butterworth, D. and Matsuda, H. 2002. Comparison of duplicate sighting rate for Southern Hemisphere whales between the 2 nd and 3rd circumpolar surveys of IWC/IDCR-SOWER. Paper SC/54/IA16 presented to the IWC Scientific Committee, April-May 2002 (unpublished). 18pp. [Available from the Office of this Journal]

Murase, H. 2014. Estimation of circumpolar spatial distributions of baleen whales in the Antarctic in the period of the IWC IDCR/SOWER CPII and CPIII (1994-2004). Paper SC/65b/IA10 presented to the IWC Scientific Committee, May 2014 (unpublished). 42pp. [Available from the Office of this Journal].

Murase, H. and Bravington, M. 2012. Potential lines of enquiry when considering changes in abundance estimates from CPII and CPIII. J. Cetacean Res Manage (Suppl.) 13: 187-88.

Murase, H., Kelly, N., Kitakado, T., Kock, K-H., Williams, R. and Walløe, L. 2012. Review of technical aspects of sea ice data which will be used to bound or estimate the abundance of Antarctic minke whales in the south of the ice edge during the period of IWC IDCR/SOWER. Paper SC/64/IA3 presented to the IWC Scientific Committee, June 2012 (unpublished). 13pp. [Available from the Office of this Journal].
Murase, H. and Kitakado, T. 2013. Consideration of an abundance estimation method of Antarctic minke whales within sea ice field using the IWC IDCR-SOWER data. Paper SC/65a/IA11 presented to the IWC Scientific Committee, June 2013 (unpublished). 12pp. [Available from the Office of this Journal].

Murase, H., Kitakado, T., Hakamada, T., Matsuoka, K., Nishiwaki, S. and Naganobu, M. 2013. Spatial distribution of Antarctic minke whales (Balaenoptera bonaerensis) in relation to spatial distributions of krill in the Ross Sea, Antarctica. Fish. Oceanogr. 22:154-73.

Murase, H., Matsuoka, K., Hakamada, T. and Kitakado, T., 2014. Preliminary analysis of changes in spatial distribution of Antarctic minke and humpback whales in Area IV during the period of JARPA and JARPAII from 1989 to 2006 . Paper SC/F14/J18 presented to the Expert Workshop to Review the Japanese JARPA II Special Permit Research Programme, February 2014 (unpublished) 17pp. [Available from the Office of this Journal].

Murase, H., Matsuoka, K., Hakamada, T., Nishiwaki, S., Wada, A. and Kitakado, T. 2011. Open sea area in the south of the ice edge in IDCR/SOWER CPII and CPIII. Paper SC/63/IA9 presented to the IWC Scientific Committee, May-June 2011 (unpublished). 16pp. [Available from the Office of this Journal].

Murase, H., Matsuoka, K., Ichii, T. and Nishiwaki, S. 2002. Relationship between the distribution of euphausiids and baleen whales in the Antarctic $\left(35^{\circ} \mathrm{E}-145^{\circ} \mathrm{W}\right)$. Polar Biol. 25:135-45.

Murase, H., Matsuoka, K., Nishiwaki, S., Hakamada, T. and Mori, M. 2004. Effects of observed covariates (school size, sighting cue, latetude and sea state) on the Antarctic minke whale abundance estimation parameters in the IWC/IDCR-SOWER surveys. J. Cetacean Res. Manage. 6: 283-92.

Murase, H. and Shimada, H. 2004a. Alternative estimation of Antarctic minke whale abundance taking account of possible animals in the unsurveyed large polynya: A case study in Area II in 1997/98. Paper SC/56/IA14, presented to the IWC Scientific Committee, June-July 2004 (unpublished). 13pp. [Available from the Office of this Journal].

Murase, H. and Shimada, H. 2004b. Possible impact due to variability of sea ice condition on Antarctic minke whale abundance estimation in the Antarctic from 1978 to 2002 . Paper SC/56/IA10, presented to the IWC Scientific Committee, June-July 2004 (unpublished). 15pp. [Available from the Office of this Journal].

Murase, H., Shimada, H. and Kitakado, T. 2005. Alternative estimation of Antarctic minke whale abundance taking account of possible animals in the unsurveyed large polynya using GAM-based spatial analysis: A case study in Area II in 1997/98 IWC/SOWER. Paper SC/57/IA6, presented to the IWC Scientific Committee, May-June 2005 (unpublished). 13pp. [Available from the Office of this Journal].

Naito, Y. 1982. Sightings records of minke whales in the pack ice and adjacent waters off the coast of Enderby Land. Rep. int. Whal. Commn 32: 929-33.

Nakamura, G., Kadowaki, I., Nagatsuka, S., Fujise, Y., Kishiro, T. and Kato, H. 2014. Variation in a color pattern of white patch on the flippers of North Pacific common minke whales: Potential application for their interoceanic difference. La Mer 52: 31-47.

Nishiwaki, S., Ishikawa, H. and Fujise, Y. 2006. Review of general methodology and survey procedure under the JARPA. Paper SC/D06/0J2 presented to the Intersessional Workshop to Review Data and Results from Special Permit Research on Minke Whales in the Antarctic, 4-8 December 2006 (unpublished). 24pp. [Available from the Office of this Journal].

Nishiwaki, S., Ishikawa, H., Goto, M., Matsuoka, K. and Tamura, T. 2014. Review of general methodology and survey procedures under the JARPAII. Paper SC/F14/J02 presented to the Expert Workshop to Review the Japanese JARPA II Special Permit Research Programme, February 2014 (unpublished). 34pp. [Available from the Office of this Journal].

Nishiwaki, S., Matsuoka, K., Kawasaki, M., Kishino, H. and Kasamatsu, F. 1997. Review of the sighting surveys in the JARPA. Paper SC/M97/1 presented to the international working group to review data and results from special permit research on minke whales in the Antarctic, May 1997 (unpublished). 42pp. [Available from the Office of this Journal].

Næss, A., Haug, T. and Nilssen, M. 1998. Seasonal variation in body condition and muscular lipid contents in Northeast Atlantic minke whale Balaenoptera acutorostrata. Sarsia 83:211-8.

Ohsumi, S. and Masaki, Y. 1974. Status of whale stocks in the Antarctic, 1972-73. Rep. int. Whal. Commn. 24: 102-13.

Ohsumi, S., Masaki, Y. and Kawamura, A. 1970. Stock of the Antarctic minke whale. Sci. Rep. Whales Res. Inst. Tokyo 22: 75-125.

Okamura, H., Kitakado, T., Hiramatsu, K. and Mori, M. 2002. A new variant of hazard probability model for abundance estimation of minke whales in the Antarctic. Paper SC/54/IA10 presented to the IWC Scientific Committee, April-May 2002 (unpublished). 28pp. [Available from the Office of this Journal].

Omura, H. 1975. Osteological study of the minke whale from the Antarctic. Sci. Rep. Whales Res. Inst. Tokyo 21:1-78. 
Palka, D. and Smith, D. 2003. Description of data simulating the IDCR/SOWER minke whale surveys. SC/55/IA9 presented to the IWC Scientific Committee, May-June 2003. (unpublished). 3pp. [Available from the Office of this Journal].

Pastene, L. 2006. What do we know about the stock structure of the Antarctic minke whale? A summary of studies and hypotheses. Paper SC/D06/J12 presented to the Expert Workshop to Review the Japanese JARPA II Special Permit Research Programme, 4-8 December 2006 (unpublished). 24pp. [Available from the Office of this Journal].

Pastene, L.A. and Goto, M. 2016. Genetic characterization and population genetic structure of the Antarctic minke whale Balaenoptera bonaerensis in the Indo-Pacific region of the Southern Ocean. Fish. Sci. 82:873-86.

Pastene, L.A., Acevedo, J., Goto, M., Zerbini, A.N., Acuna, P. and AguayoLobo, A. 2010. Population structure and possible migratory links of common minke whales, Balaenoptera acutorostrata, in the Southern Hemisphere. Conservation Genet. 11:1553-58.

Pastene, L.A., Fujise, Y. and Numachi, K. 1994. Differentiation of mitochondrial DNA between ordinary and dwarf forms of southern minke whale. Rep. int. Whal. Commn 44:277-81.

Pastene, L.A., Goto, M., Itoh, S. and Numachi, K. 1996. Spatial and temporal patterns of mitochondrial DNA variation in minke whale from Antarctic Areas IV and V. Rep. int. Whal. Commn 46:305-14.

Pastene, L.A., Goto, M. and Kanda, N. 2006. Genetic analysis on stock structure in the Antarctic minke whales from the JARPA research area based on mitochondrial DNA and microsatellites. Paper SC/D06/J9 presented to the Intersessional Workshop to Review Data and Results from Special Permit Research on Minke Whales in the Antarctic, Tokyo December 2006. (unpublished) 22pp. [Available from the Office of this Journal].

Pastene, L.A., Goto, M., Kanda, N., Zerbini, A.N., Kerem, D., Watanabe, K., Bessho, Y., Hasegawa, M., Nielsen, R., Larsen, F. and Palsboll, P.J. 2007. Radiation and speciation of pelagic organisms during periods of global warming: the case of the common minke whale, Balaenoptera acutorostrata. Mol. Ecol. 16:1481-95.

Pastene, L.A., Kobayashi, T., Fujise, Y. and Numachi, K. 1993 Mitochondrial DNA differentiation in Antarctic minke whales. Rep. int Whal. Commn. 43:349-55.

Pitman, R.L. and Ensor, P. 2003. Three forms of killer whales (Orcinus orca) in Antarctic waters. J. Cetacean Res. Manage. 5: 131-9.

Punt, A.E. 2014. A summary history of the application of Statistical CatchAt-Age Analysis to Antarctic minke whales J. Cetacean. Res. Manage. 14:81-92.

Punt, A.E., Hakamada, T., Bando, T. and Kitkado, T. 2014. Assessment of Antarctic minke whales using Statistical Catch-at-age Analysis (SCAA). J. Cetacean Res. Manage. 14:93-116.

Punt, A.E. and Polacheck, T. 2005. Application of statistical catch-at-age analysis for Southern Hemisphere minke whales in Antarctic Areas IV and V. Paper SC/57/IA9 presented to the IWC Scientific Committee, June 2005 (unpublished) 71pp. [Available from the Office of this Journal].

Punt, A.E. and Polacheck, T. 2006. Further statistical catch-at-age analyses for Southern Hemisphere minke whales. Paper SC/58/IA2 presented to the IWC Scientific Committee, May-June 2006 (unpublished) 40pp. [Available from the Office of this Journal].

Rademeyer, R.A. and Butterworth, D.S. 2002. Miscellaneous aspects of minke whale abundance estimation for the IDCR-SOWER surveys. Paper SC/54/IA29 presented to the IWC Scientific Committee, April-May 2002 (unpublished). [Available from the Office of this Journal].

Reilly, S., Hedley, S., Borberg, J., Hewitt, R., Thiele, D., Watkins, J. and Naganobu, M. 2004. Biomass and energy transfer to baleen whales in the South Atlantic sector of the Southern Ocean. Deep Sea Res. II. 51:1397409.

Ribic, C. A., Ainley, D. G. and Fraser, W. R. 1991. Habitat selection by marine mammals in the marginal ice zone. Antarct. Sci. 3:181-6.

Rice, D.W. 1998. Marine Mammals of the World: Systematics and Distribution. Special Publication Number 4, The Society for Marine Mammalogy. Allen Press, USA. 231pp.

Sakuramoto, K. and Tanaka, S. 1985. A new multi-cohort method for estimating Southern Hemisphere minke whale populations. Rep. int Whal. Commn 35:261-71.

Sakuramoto, K. and Tanaka, S. 1986. Further development of an assessment technique for Southern Hemisphere minke whale populations using a multi-cohort method. Rep. int. Whal. Commn 36:207-12.

SC-CAMLR. 2011. Report of the Working Group on Fish Stock Assessment (Appendix N: Fishery Report: Exploratory fishery for Dissostichus spp.in Division 58.4.1). In: Report of the Thirtieth Meeting of the Scientific Committee (SC-CAMLR-XXX), Annex 7. CCAMLR, Hobart, Australia. $14 \mathrm{pp}$

Scheidat, M., Friedlaender, A., Kock, K.-H., Lehnert, L., Boebel, O., Roberts, J. and Williams, R. 2011. Cetacean surveys in the Southern Ocean using icebreaker-supported helicopters. Polar Biol. 34:1513-22.
Schmitt, N.T., Double, M.C., Jarman, S.N., Gales, N., Marthick, J.R., Polanowski, A.M., Baker, C.S., Steel, D., Jenner, K.C.S., Jenner, M.N.M., Gales, R., Paton, D. and Peakall, R. 2012. Low levels of genetic differentiation characterize Australian humpback whale (Megaptera novaeangliae) populations. Mar. Mamm. Sci. 30:221-41.

Schweder, T., Kitakado, T., Kanda, N., Pastene, L. and Walloe, L. 2011. Dynamic population segregation by genetics and morphometrics in Antarctic minke whales. Paper SC/63/IA7 presented to the IWC Scientific Committee. May-June 2011 (unpublished). 20pp. [Available from the Office of this Journal].

Sekiguchi, K., Fukutome, K., Morse, L., Shinyashiki, Y. and Oedekoven, C. 2010. Report of the 2009-2010 International Whaling CommissionSouthern Ocean Whale and Ecosystem Research (IWC-SOWER) Cruise. Paper SC/62/IA1 presented to the IWC Scientific Committee, May-June 2010 (unpublished). $51 \mathrm{pp}$. [Available from the Office of this Journal].

Shimada, H. and Burt, M. 2007. Relationship between minke whale abundance and pack ice extent examined by $10^{\circ}$ longitudinal slices. Paper SC/59/IA26, presented to the IWC Scientific Committee, May 2007 (unpublished). 5pp. [Available from the Office of this Journal].

Shimada, H. and Kato, A. 2005. Preliminary report on a sighting survey of Antarctic minke whale within ice field conducted by the ice breaker, Shirase in 2004/2005. Paper SC/57/IA7 presented to the IWC Scientific Committee, May-June 2005 (unpublished). 14pp. [Available from the Office of this Journal]

Shimada, H. and Kato, A. 2006. Tentative population assessment of the Antarctic minke whale within ice field using sighting data on the ice breaker Shirase in 2004/2005. Paper SC/58/IA11 presented to the IWC Scientific Committee, May-June 2006 (unpublished). 10pp. [Available from the Office of this Journal].

Shimada, H. and Kato, A. 2007. Population assessment of the Antarctic minke whale within and out of ice field using a sighting data on the Ice Breaker and the IWC SOWER vessels in 2004/2005. Paper SC/59/IA16, presented to the IWC Scientific Committee, May 2007 (unpublished) $8 \mathrm{pp}$. [Available from the Office of this Journal]

Shimada, H. and Murase, H. 2002. Some analysis on sea ice condition in relation to changes in the Antarctic minke whale distribution pattern in the Antarctic Area IV. Paper SC/54/IA18 presented to the IWC Scientific Committee, April-May 2002 (unpublished). 8pp. [Available from the Office of this Journal]

Shimada, H. and Murase, H. 2003. Further examination of sea ice condition in relation to changes in the Antarctic minke whale distribution pattern in the Antarctic Area IV. Paper SC/55/IA7 presented to the IWC Scientific Committee, May-June 2003. (unpublished). 3pp. [Available from the Office of this Journal]

Shimada, H. And Murase, H. 2006. Relationship between minke whale abundance and pack ice extent. Paper SC/58/IA12 presented to the IWC Scientific Committee, May-June 2006 (unpublished). 7pp. [Available from the Office of this Journal].

Shimada, H., Segawa, K. and Murase, H. 2001. Tentative trial for estimation of Antarctic minke whale abundance within pack ice region incorporating IDCR/SOWER data with meteorological satellites data. Paper SC/53/IA14 presented to the IWC Scientific Committee, July 2001 (unpublished). 6pp. [Available from the Office of this Journal].

Shimada, H., Segawa, K. and Murase, H. 2002. A preliminary trial: estimation of the Antarctic minke whale abundance within the sea ice area incorporating IDCR/SOWER data with meteorological satellites data. Paper SC/54/IA19 presented to the IWC Scientific Committee, April-May 2002 (unpublished). 6pp. [Available from the Office of this Journal]

Strindberg, S. and Burt, L. 2004. IWC Database-Estimation Software System (DESS): User Manual. University of St Andrews, St Andrews. $450 \mathrm{pp}$

Tamura, T. and Konishi, K. 2009. Feeding habits and prey consumption of Antarctic minke whale (Balaenoptera bonaerensis) in the Southern Ocean. J. N. Atl. Fish. Sci. 42:13-25.

Tamura, T. and Konishi, K. 2014. Prey composition and consumption rate by Antarctic minke whales based on JARPA and JARPAII data. Paper SC/F14/J15 presented to the Expert Workshop to Review the Japanese JARPA II Special Permit Research Programme, February 2014 (unpublished). 20pp. [Available from the Office of this Journal].

Tamura, T., Konishi, K., Isoda, T., Okamoto, R., Bando, T. and Hakamada, T. 2009. Some examinations of uncertainties in the prey consumption estimates of common minke, sei and Bryde's whales in the western North Pacific. Paper SC/61/JR2 presented to the IWC Scientific Committee, June 2009 (unpublished). 24pp. [Available from the Office of this Journal].

Tanaka, E., Zenitani, R., Hakamada, T. and Fujise, Y. 2006. An estimate of average natural mortality coefficient of Antarctic minke whales using JARPA data. Paper SC/D06/J13 presented to the Intersessional Workshop to Review Data and Results from Special Permit Research on Minke 
Whales in the Antarctic, December 2006 (unpublished). 12pp. [Available from the Office of this Journal].

Tanaka, S. 1990. Estimation of natural mortality coefficient of whales from the estimates of abundance and age composition data obtained from research catches. Rep. int. Whal. Commn 40:531-6.

Taylor, R.J.F. 1957. An unusual record of three species of whale being restricted to pools in Antarctic sea-ice. Proc. Zool. Soc. Lond. 129:325-31.

Thiele, D. and Gill, P.C. 1999. Cetacean observations during a winter voyage into Antarctic sea ice south of Australia. Antarct. Sci. 11:48-53.

Thiele, D., Chester, E.T. and Asmus, K. 2005. Antarctic sea ice: measuring habitat complexity, and seasonal and regional variability in habitat use for minke whales. Paper SC/57/E1 presented to the IWC Scientific Committee, May-June 2005 (unpublished). 21pp. [Available from the Office of this Journal].

Thiele, D., Chester, E. and Friedlaender, A. 2002. Antarctic sea-ice habitat for minke whales (Balaenoptera acutorostrata $\mathrm{sp}$.). Results of a line transect survey in East Antarctica. Paper SC/54/IA6 presented to the IWC Scientific Committee, April-May 2002 (unpublished). 14pp. [Available from the Office of this Journal].

Thomson, R.B., Butterworth D.S. and Kato, H. 1999. Has the age transition of southern hemisphere minke whales declined over recent decades? Mar. Mamm. Sci. 15: 661-82.

van Utrecht, W.L. and van der Spoel, S. 1962. Observations on a minke whale (Mammalia, Cetacea) from the Antarctic. Z. Saugetierkd 27: 21721.

Wada, S., Kobayashi, T. and Numachi, K. 1991. Genetic variability and differentiation of mitochondrial DNA in minke whales. Rep. int. Whal. Commn (special issue) 13: 203-15.

Williams, R., Kelly, N., Boebel, O., Friedlaender, A.S., Herr, H., Kock, K.H., Lehnert, L.S., Maksym, T., Roberts, J., Scheidat, M., Siebert, U. and Brierley, A.S. 2014. Counting whales in a challenging, changing environment. Sci. Rep. 4: 4170. [https://doi.org/10.1038/srep04170]
Williamson, G.R. 1959. Three unusual rorqual whales from the Antarctic. Proc. Zool. Soc., Lond. 133:135-44.

Yasunaga, G., Bando, T. and Fujise, Y. 2014a. Pattern of organochlorine accumulation in the Antarctic minke whale based on JARPAII data. Paper SC/F14/J24 presented to the Expert Workshop to Review the Japanese JARPA II Special Permit Research Programme, February 2014 (unpublished). 7pp. [Available from the Office of this Journal].

Yasunaga, G., Bando, T. and Fujise, Y. 2014b. Pattern of mercury accumulation in the Antarctic minke whale and its prey based on JARPAII data. Paper SC/F14/J23 presented to the Expert Workshop to Review the Japanese JARPA II Special Permit Research Programme, February 2014 (unpublished). 7pp. [Available from the Office of this Journal].

Yasunaga, G., Fujise, Y., Zenitani, R., Honda, K. and Kato, H. 2006. Yearly trend of trace element accumulation in liver of Antarctic minke whale, Balaenoptera bonaerensis. Paper SC/D06/J28 presented to the Intersessional Workshop to Review Data and Results from Special Permit Research on Minke Whales in the Antarctic, December 2006 (unpublished). 23pp. [Available from the Office of this Journal].

Yasunaga, G., Fujise, Y., Zenitani, R., Tanabe, S. and Kato, H. 2015. Spatial and temporal variation of PCBs and organochlorine pesticides in the Antarctic minke whales, Balaenoptera bonaerensis, in the period 19872005. Chemosphere 126:11-17.

Yasunaga, G., Pastene, L.A., Bando, T., Hakamada, T. and Fujise, Y. 2017. Age estimation of Antarctic minke whales Balaenoptera bonaerensis based on aspartic acid racemization technique. Fish. Sci. 83: 947-54.

Zenitani, R. and Kato, H. 2006. Temporal trend of age at sexual maturity of Antarctic minke whales based on transition phase in earplugs obtained under JARPA surveys from 1987/88-2004/05. Paper SC/D06/J15 presented to the Intersessional Workshop to Review Data and Results from Special Permit Research on Minke Whales in the Antarctic, December 2006 (unpublished). 9pp. [Available from the Office of this Journal]. 